\title{
Recalibration of the Shear Stress Transport Model to Improve Calculation of Shock Separated Flows
}

Nicholas J. Georgiadis and Dennis A. Yoder

Glenn Research Center, Cleveland, Ohio 


\section{NASA STI Program . . . in Profile}

Since its founding, NASA has been dedicated to the advancement of aeronautics and space science. The NASA Scientific and Technical Information (STI) program plays a key part in helping NASA maintain this important role.

The NASA STI Program operates under the auspices of the Agency Chief Information Officer. It collects, organizes, provides for archiving, and disseminates NASA's STI. The NASA STI program provides access to the NASA Aeronautics and Space Database and its public interface, the NASA Technical Reports Server, thus providing one of the largest collections of aeronautical and space science STI in the world. Results are published in both non-NASA channels and by NASA in the NASA STI Report Series, which includes the following report types:

- TECHNICAL PUBLICATION. Reports of completed research or a major significant phase of research that present the results of NASA programs and include extensive data or theoretical analysis. Includes compilations of significant scientific and technical data and information deemed to be of continuing reference value. NASA counterpart of peer-reviewed formal professional papers but has less stringent limitations on manuscript length and extent of graphic presentations.

- TECHNICAL MEMORANDUM. Scientific and technical findings that are preliminary or of specialized interest, e.g., quick release reports, working papers, and bibliographies that contain minimal annotation. Does not contain extensive analysis.

- CONTRACTOR REPORT. Scientific and technical findings by NASA-sponsored contractors and grantees.
- CONFERENCE PUBLICATION. Collected papers from scientific and technical conferences, symposia, seminars, or other meetings sponsored or cosponsored by NASA.

- SPECIAL PUBLICATION. Scientific, technical, or historical information from NASA programs, projects, and missions, often concerned with subjects having substantial public interest.

- TECHNICAL TRANSLATION. Englishlanguage translations of foreign scientific and technical material pertinent to NASA's mission.

Specialized services also include creating custom thesauri, building customized databases, organizing and publishing research results.

For more information about the NASA STI program, see the following:

- Access the NASA STI program home page at http://www.sti.nasa.gov

- E-mail your question to help@sti.nasa.gov

- Fax your question to the NASA STI Information Desk at 443-757-5803

- Phone the NASA STI Information Desk at 443-757-5802

- Write to: STI Information Desk NASA Center for AeroSpace Information 7115 Standard Drive Hanover, MD 21076-1320 


\section{Recalibration of the Shear Stress Transport Model to Improve Calculation of Shock Separated Flows}

Nicholas J. Georgiadis and Dennis A. Yoder

Glenn Research Center, Cleveland, Ohio

Prepared for the

51st Aerospace Sciences Meeting

sponsored by the American Institute of Aeronautics and Astronautics

Grapevine, Texas, January 7-10, 2013

National Aeronautics and

Space Administration

Glenn Research Center

Cleveland, Ohio 44135 


\section{Acknowledgments}

This work was supported by the Aeronautical Sciences Project of the NASA Fundamental Aeronautics Program.

This work was sponsored by the Fundamental Aeronautics Program at the NASA Glenn Research Center.

Level of Review: This material has been technically reviewed by technical management.

Available from

NASA Center for Aerospace Information 7115 Standard Drive

Hanover, MD 21076-1320
National Technical Information Service 5301 Shawnee Road Alexandria, VA 22312

Available electronically at http://www.sti.nasa.gov 


\title{
Recalibration of the Shear Stress Transport Model to Improve Calculation of Shock Separated Flows
}

\author{
Nicholas J. Georgiadis and Dennis A. Yoder \\ National Aeronautics and Space Administration \\ Glenn Research Center \\ Cleveland, Ohio 44135
}

\begin{abstract}
The Menter Shear Stress Transport (SST) $k-\omega$ turbulence model is one of the most widely used two-equation Reynolds-averaged Navier-Stokes turbulence models for aerodynamic analyses. The model extends Menter's baseline (BSL) model to include a limiter that prevents the calculated turbulent shear stress from exceeding a prescribed fraction of the turbulent kinetic energy via a proportionality constant, $a_{1}$, set to 0.31. Compared to other turbulence models, the SST model yields superior predictions of mild adverse pressure gradient flows including those with small separations. In shock - boundary layer interaction regions, the SST model produces separations that are too large while the BSL model is on the other extreme, predicting separations that are too small. In this paper, changing $a_{1}$ to a value near 0.355 is shown to significantly improve predictions of shock separated flows. Several cases are examined computationally and experimental data is also considered to justify raising the value of $a_{1}$ used for shock separated flows.
\end{abstract}

\section{Nomenclature}

$\begin{array}{ll}C_{f} & \text { skin friction coefficient } \\ C_{l i m} & \text { shear stress limiting coefficient } \\ d & \text { distance from wall } \\ H & \text { backward facing step height } \\ k & \text { turbulent kinetic energy } \\ \mathcal{P}_{k} & \text { production of turbulent kinetic energy } \\ R e_{x} & \text { plate Reynolds number } \\ S_{i j} & \text { mean rate of strain tensor } \\ t & \text { time } \\ U_{j} & \text { mean velocity vector } \\ U_{\infty} & \text { mean freestream velocity } \\ u^{+} & \text {velocity normalized with wall shear stress } \\ u_{i}^{\prime} & \text { fluctuating velocity vector } \\ u^{\prime}, v^{\prime}, w^{\prime} & \text { fluctuating velocity components } \\ W_{i j} & \text { mean vorticity tensor } \\ x, y, z & \text { Cartesian coordinates } \\ y^{+} & \text {wall normal coordinate } \\ \delta_{u} & \text { boundary layer thickness for UFAST test case just upstream of shock generator } \\ \epsilon & \text { turbulent dissipation rate } \\ \kappa & \text { von Karman constant } \\ \mu & \text { dynamic viscosity } \\ \mu_{t} & \text { dynamic eddy viscosity } \\ \omega & \text { specific turbulent dissipation rate }=\epsilon / k \\ \Omega & \text { vorticity magnitude } \\ \rho & \text { density } \\ \tau_{i j}^{T} & \text { turbulent stress tensor }\end{array}$




\section{Introduction}

Despite extensive efforts in the aerodynamics community over more than two decades, the prediction of flow separation remains elusive. In supersonic flows, the shock wave / turbulent boundary layer interaction (SWTBLI) produces especially complex flow separations that have significant effects on the operability of specific components such as aircraft inlets and also on overall performance of aerospace vehicles. A recent workshop considering CFD calculations for a set of SWTBLI cases was held in conjunction with the 48th American Institute of Aeronautics and Astronautics (AIAA) Aerospace Sciences Meeting. The focus of this workshop ${ }^{1,2}$ was SWTBLI as occurs in supersonic inlets. Several investigators contributed solutions to this workshop including both Reynolds-averaged Navier-Stokes (RANS) computations and LargeEddy Simulations (LES) computations. DeBonis et $\mathrm{al}^{3}$ provides a comprehensive assessment of the CFD calculations, including uncertainty analysis of the submitted CFD results and experimental data obtained for the same configurations. The results of the workshop indicated that none of the RANS methods were able to capture the details of the SWTBLIs and that LES, while offering promise for the future, still cannot be applied to configurations at realistic Reynolds numbers.

Of the RANS turbulence models applied to the SWTBLI cases in the workshop, the most commonly used model by the participants was the two-equation Shear Stress Transport (SST) model of Menter. ${ }^{4}$ The SST model is a $\mathrm{k}-\omega$ formulation that has become one of the most widely used turbulence models for RANS analyses. It has been shown to be robust and relatively accurate for a broad range of flows, including wall boundary layers and free shear layers. For small separations due to mild adverse pressure gradients in subsonic flows, the model has demonstrated success. As observed in the results of the workshop and elsewhere, however, the SST model tends to over-predict the size of flow separations in SWTBLI problems. In Ref. 4, Menter also introduced a similar k- $\omega$ model without a stress limiter, called the baseline (BSL) model, which conversely tends to underpredict the magnitude of shock-induced separations.

Because the BSL and SST formulations predict significant differences in shock induced flow separations, on opposite extremes of the experimental data, we investigated the distinguishing aspect of the SST model, the shear stress limiter, in this paper. Details of the Menter SST model and background of the shear stress limiter that has made the model so popular are described. It is shown that for flows with shock-induced separations, a minor adjustment to the key coefficient in the shear stress limiter enables improved predictions of flows containing SWTBLIs.

\section{Menter SST Model}

For nearly two decades, the practical state-of-the-art in RANS turbulence modeling has been two-equation eddy viscosity turbulence models. In these linear eddy viscosity models, the Boussinesq approximation is used to relate the turbulent Reynolds stress to the mean rate of strain tensor through a turbulent (or eddy) viscosity. The SST model is a two-layer eddy viscosity model which employs the original (commonly referred to as the 1988 version) of the $k-\omega$ model of Wilcox ${ }^{5}$ in the inner region of boundary layers and switches to a $k-\epsilon$ model in the outer region of boundary layers and in mixing regions. The outer $k-\epsilon$ model is transformed to the $k-\omega$ form with a blending function used to transition between the two layers.

$$
\begin{aligned}
\frac{\partial(\rho k)}{\partial t}+\frac{\partial\left(\rho U_{j} k\right)}{\partial x_{j}} & =\mathcal{P}_{k}-\beta^{*} \rho \omega k+\frac{\partial}{\partial x_{j}}\left(\left(\mu+\sigma_{k} \mu_{t}\right) \frac{\partial k}{\partial x_{j}}\right) \\
\frac{\partial(\rho \omega)}{\partial t}+\frac{\partial\left(\rho U_{j} \omega\right)}{\partial x_{j}} & =\frac{\gamma}{\nu_{t}} \mathcal{P}_{k}-\beta \rho \omega^{2}+\frac{\partial}{\partial x_{j}}\left(\left(\mu+\sigma_{\omega} \mu_{t}\right) \frac{\partial \omega}{\partial x_{j}}\right)+2\left(1-F_{1}\right) \rho \sigma_{\omega 2} \frac{1}{\omega} \frac{\partial k}{\partial x_{j}} \frac{\partial \omega}{\partial x_{j}} \\
\mathcal{P}_{k} & =\tau_{i j}^{T} \frac{\partial u_{i}}{\partial x_{j}} \\
\tau_{i j}^{T} & =\mu_{t}\left(2 S_{i j}-\frac{2}{3} \frac{\partial u_{k}}{\partial x_{k}} \delta_{i j}\right)-\frac{2}{3} \rho k \delta_{i j}
\end{aligned}
$$




$$
\begin{aligned}
S_{i j} & =\frac{1}{2}\left(\frac{\partial u_{j}}{\partial x_{i}}+\frac{\partial u_{i}}{\partial x_{j}}\right) \\
F_{1} & =\tanh \left[\left(\arg _{1}\right)^{4}\right] \\
\arg _{1} & =\min \left(\max \left(\frac{\sqrt{k}}{\beta^{*} \omega d} ; \frac{500 \nu}{\omega d^{2}}\right) ; \frac{4 \rho \sigma_{\omega 2} k}{C D_{k \omega} d^{2}}\right) \\
C D_{k \omega} & =\max \left(2 \rho \sigma_{\omega 2} \frac{1}{\omega} \frac{\partial k}{\partial x_{j}} \frac{\partial \omega}{\partial x_{j}} ; 1.0 \times 10^{-20}\right)
\end{aligned}
$$

and from these the turbulent viscosity is given as

$$
\mu_{t}=\frac{\rho a_{1} k}{\max \left(a_{1} \omega ; \Omega F_{2}\right)}=\frac{\rho k}{\max \left(\omega ; \Omega F_{2} / a_{1}\right)}
$$

where

$$
\begin{aligned}
F_{2} & =\tanh \left[\left(\arg _{2}\right)^{2}\right] \\
\arg _{2} & =\min \left(2 \frac{\sqrt{k}}{\beta^{*} \omega d} ; \frac{500 \nu}{\omega d^{2}}\right)
\end{aligned}
$$

The constants for the inner mode (set 1) are as follows:

$$
\gamma_{1}=\frac{\beta_{1}}{\beta^{*}}-\frac{\sigma_{\omega 1} \kappa^{2}}{\sqrt{\beta^{*}}}, \quad \sigma_{k 1}=0.85, \quad \sigma_{\omega 1}=0.5, \quad \beta_{1}=0.075,
$$

and the constants $\left(\phi_{2}\right)$ for the transformed $k-\epsilon$ model (set 2) are:

$$
\gamma_{2}=\frac{\beta_{2}}{\beta^{*}}-\frac{\sigma_{\omega 2} \kappa^{2}}{\sqrt{\beta^{*}}}, \quad \sigma_{k 2}=1.00, \quad \sigma_{\omega 2}=0.856, \quad \beta_{2}=0.0828,
$$

These constants are blended using the same switching function, $F_{1}$ that is found in the model equations such that $\phi=F_{1} \phi_{1}+\left(1-F_{1}\right) \phi_{2}$ for any of the given parameters. The remaining constants have the following values:

$$
\beta^{*}=0.09, \quad \kappa=0.41, \quad a_{1}=0.31,
$$

The SST turbulence model has become popular for its accuracy and applicability to complex geometry due to the strengths of the $k-\omega$ model in the near wall region, and $k-\epsilon$ model in free shear layers. The BSL model also introduced by Menter, ${ }^{4}$ is identical to the SST model with two exceptions. First, the value for $\sigma_{k 1}$ in set 1 is set to 0.5 , which is the same as in the original Wilcox model. ${ }^{5}$ Secondly, the turbulent viscosity is simply $\mu_{t}=\rho k / \omega$. Referring back to Eqn. 9, the SST model employs a "shear stress limiter" to prevent the calculated turbulent shear stress from exceeding a prescribed fraction of the turbulent kinetic energy. It is this term that we focus on in this paper, for while the SST model has demonstrated success for mild adverse pressure gradient flows, the prediction of SWTBLIs has generally resulted in shock-induced separations that are much larger than those measured in experiments.

\section{Shear Stress Limiter}

Menter ${ }^{4}$ remarked that one of the primary deficiencies of eddy-viscosity models, in comparison to full Reynolds-stress closures, is that they do not account for the transport of the turbulent shear stress. Menter refers to the "Bradshaw Assumption" where the turbulent shear stress in a boundary layer is proportional to the turbulent kinetic energy through a constant as shown in Eqn. 12: 


$$
\tau=-\rho \overline{u^{\prime} v^{\prime}}=\rho a_{1} k
$$

The proportionality constant, $a_{1}$, used in the limiter for the SST model, is also commonly referred to as the structure parameter, or the "Townsend ${ }^{6}$ structure parameter." In the literature, the former is usually defined as $-\overline{u^{\prime} v^{\prime}}=a_{1} q$ where $q=2 k$, and $a_{1}$ will be half of the value corresponding to that used in Eqn. 12 . Here, we will refer to the form denoted by Eqn. 12 when discussing the limiter or the experimental findings in the following sections. Because two-equation turbulence models calculate the turbulent shear stress from Eqn. 4 or the nearly approximate form using the vorticity magnitude, $\Omega$, Eqn. 9 limits the eddy viscosity calculated by the model to the smaller of $\rho k / \omega$ and $\rho a_{1} k / \Omega F_{2}$. As shown in Ref. 7 the $F_{2}$ function is unity in the inner three-fourths of a zero-pressure gradient boundary layer and drops to zero outside boundary layers so that no limiting is performed outside boundary layers.

It is obvious then that the selection for the value of the proportionality constant, $a_{1}$, is crucial to the performance of the SST model. Menter selected $a_{1}=0.31$ as the standard value for the SST model. Coakley ${ }^{8}$ developed a $q-\omega$ model which also used a shear stress limiter with a value for this constant of 0.30 . Both the Coakley and Menter models followed the work of Bradshaw et al. ${ }^{9}$ where a one-equation model was formulated based on the same relation of the turbulent shear stress to the turbulent kinetic energy via a structure parameter set to approximately 0.30. Bradshaw et al. ${ }^{9}$ and Bradshaw ${ }^{10}$ utilize experimental data of Klebanoff ${ }^{11}$ to illustrate that this value of the structure parameter is characteristic of zero pressure gradient flat plate boundary layers. For mild adverse pressure gradients, Aubertine and Eaton ${ }^{12}$ as well as Alving and Fernholz ${ }^{13}$ show that as the flow passes through an adverse pressure gradient and even small separation, the structure parameter actually drops from the zero-pressure gradient value, before recovering further downstream of reattachment.

The success of the SST model using $a_{1}=0.31$ relative to the otherwise similar BSL model, has been well demonstrated by Menter ${ }^{4}$ and many other investigators for attached boundary layers or mild adverse pressure gradient flows leading to relatively small separations. The motivation here is to examine the effect of the shear stress limiter, and the original value of $a_{1}$ that was set to 0.31 , for flows outside these regimes and in particular to focus on the SWTBLI problem.

The value of $a_{1}$ for a homogenous free shear layer flow investigated by Rose ${ }^{14}$ was found to be approximately 0.35. Bradshaw ${ }^{10}$ concluded that the empirical relationship between turbulent shear stress and turbulent kinetic energy for boundary layers that are attached, or nearly so, is not likely valid for other turbulent flows. The fact that the SST model employs the $F_{2}$ function enables the shear stress limiter to be turned off outside boundary layers, which is an advantage of the hybrid model formulation.

Other reported efforts have investigated a different value than $a_{1}=0.31$ for shock-boundary layer dominated flows. In the most recent version of Wilcox's $k-\omega$ model, ${ }^{15,16}$ commonly referred to as the Wilcox $2006 k-\omega$ model, a shear stress limiter is introduced. This limiter differs from Menter's formulation in that it uses (1) the rate-of-strain tensor instead of vorticity, and (2) a coefficient $C_{l i m}$ rather than $a_{1}$. For shear dominated flows, the effective structure parameter is given by Eqn. 13.

$$
a_{1}=\frac{1}{C_{l i m}} \sqrt{\beta^{*}}
$$

Using Wilcox's model coefficients yields a value of $a_{1}=0.342$. Wilcox also mentions that he examined using the vorticity magnitude with effective $a_{1}$ set to about 0.316 .

Another significant difference between the Wilcox and Menter models is that this limiter is applied everywhere, while in the Menter SST model the $F_{2}$ function only applies the shear stress limiter in the boundary layer. Tan and Jin $^{17}$ investigated the SST model with variations in $a_{1}$ also expressed through the context of the $C_{\text {lim }}$ parameter and concluded that a constant value for $a_{1}$ was not likely. Edwards et al. ${ }^{18}$ investigated variations in the effective $a_{1}$ used by SST as the inner model portion of a hybrid RANS-LES formulation and concluded that $a_{1}=0.356$ provided the best agreement with experimental results for a Mach 5 compression corner problem.

It should also be noted that algebraic Reynolds stress models inherently act to reduce the Reynolds shear stress in similar circumstances. This stress limiter is not a hard limit like those discussed above, but is instead a function of local flow invariants and the coefficients used to model higher-order terms such as the pressure-strain correlation. Wilcox ${ }^{16}$ provides a brief analysis of results from this class of model. Such modeling efforts are beyond the scope of the present work, but may hold promise for the future. 
While the work reported in this paper is not the first study to investigate the effect of the shear stress limiter on calculation of shock separated flows, it is the first study we are aware of that examines the details of turbulent statistics measured in the experiments alongside the computational results to determine a more appropriate setting for the stress limiter constant in flows where shock-boundary layer interactions are a key flow feature.

\section{Structure Parameter in SWTBLI Regions}

For SWTBLI flows, there is experimental evidence that the structure parameter can significantly exceed the values that are typical of the aforementioned boundary layer problems. Smits and Muck ${ }^{19}$ present results for a series of compression corner flows and note that the peak value for the structure parameter $a^{\prime \prime}$ given by $-\overline{u^{\prime} v^{\prime}} \sqrt{u^{\prime 2}}$ may increase by over a factor of two with the peak location occurring in the outer part of the boundary layer. Smits and Muck, ${ }^{19}$ Jayaram et al., ${ }^{20}$ and Kuntz et al. ${ }^{21}$ show that the SWTBLI creates a large amplification in the turbulent stresses, which increases with compression corner turning angle for a fixed incoming freestream Mach number.

In our experience applying the Menter BSL and SST formulations to SWTBLI problems of the 2010 AIAA workshop ${ }^{22}$ as well as that of other participating groups summarized in Ref. 3, it was generally found that the BSL and SST models provided predictions on either side of the experimental measurements. In particular, the BSL model underpredicted the magnitude of the separation while the SST model, using the standard $a_{1}$ value of 0.31 significantly overpredicted the size of the separation. The objective of the present work is to determine if there is a more optimal choice for the value of $a_{1}$ used within the context of the Menter SST model. Clearly the success of this model is largely due to use of the shear stress limiter for many flows. However, as illustrated by the experimental observations discussed in this section, there is evidence that limiting $a_{1}$ to 0.31 for SWTBLI dominated flows may prohibit correct values for the turbulent shear stress to be modeled.

\section{Results}

In this section, we first examine variations in the $a_{1}$ parameter for an incompressible flat plate flow, low speed axisymmetric diffuser, and incompressible backward facing step. Focus is then moved to SWTBLI, which is the target flow problem of interest. In the process of examining these flows, it was found that values of $a_{1}$ greater than 0.40 were very similar to the unbounded BSL model. Therefore, the range of $a_{1}$ investigated here was restricted to $0.31 \leq a_{1} \leq 0.40$.

\section{Flat Plate Boundary Layer}

A nearly incompressible flat plate flow was investigated with freestream Mach number set to 0.2 in order to provide reasonable convergence with the compressible flow solver. For this case and the next two benchmark low subsonic test cases, grids and boundary conditions that are available on the turbulence modeling website described in Ref. 23 were employed. All of the grids were previously verified to yield grid independent solutions.

In addition to variations in $a_{1}$, it was noted in an earlier section that $\sigma_{k 1}$ for the inner model also differs between the BSL and SST models. For completeness then, a BSL case was run to investigate the effect of this coefficient, which controls the diffusion of turbulent kinetic energy. The skin friction coefficient along the flat plate is shown in Fig. 1 and velocity profile is shown in Fig. 2. Both are compared with data of Wieghardt and Tillman. ${ }^{24}$ The line denoted by only "SST" in the legend of this and subsequent figures has $a_{1}=0.31$ as in the default model. The skin friction plot shows that there is minimal change in the BSL results due to changing $\sigma_{k 1}$ from 0.5 to 0.85 .

More details of the actual turbulence model behavior are shown in the plots of eddy viscosity in Fig. 3 and turbulent shear stress normalized by the turbulent kinetic energy (or effective structure parameter, $\left.a_{1}\right)$ in Fig. 4. The experimental data in Fig. 4 is taken from Klebanoff ${ }^{11}$ but is for nearly an identical plate Reynolds number, 4.2e6, as for the mean velocity profile in Fig. 2. The SST model produces the smallest values of eddy viscosity, which is due to the limiting behavior when using $a_{1}=0.31$. The inflection in the eddy viscosity and discontinuity in the slope of the turbulent shear stress for the SST solution near $y+=2000$ is due to the switch from inner model to outer model via the $F_{2}$ function. The "SST" solutions where $a_{1}$ is 0.34 or higher are indistinguishable because the shear stress limiter is never reached. These 
solutions also match the BSL solution with $\sigma_{k 1}$ changed to 0.85 , as expected. The BSL solution with $\sigma_{k 1}$ set to its standard value of 0.5 allows for less diffusion of turbulent kinetic energy, also as expected.

\section{Axisymmetric Separated Diffuser}

Perhaps the case which most clearly made a distinction between the SST formulation and other two-equation models in Menter ${ }^{4}$ was the Driver axisymmetric diffuser. ${ }^{25,26}$ In particular, the advantage of using a shear stress limiter in conjunction with the Menter SST model was demonstrated. This case considered a Mach 0.088 flow over a cylinder aligned with the flow, with an adverse pressure gradient established by diverging the tunnel walls. The case is typically run in axisymmetric mode by establishing an outer streamline believed to accurately replicate the otherwise three-dimensional flow case.

Utilizing the verified grid available from Rumsey et al. ${ }^{23}$ calculations were performed using the original SST and BSL formulations as well as SST with variations in $a_{1}$. The pressure distribution plot in Fig. 5 shows nearly identical results to those originally shown by Menter ${ }^{4}$ and clearly shows the superior result enabled by the SST solution with the standard value for $a_{1}$ compared to all of the other solutions which nearly collapse to a single line. The skin friction comparison in Fig. 6 also shows that the Menter SST model case differs from the others, which are all collapsing to the same solution, and indicates the largest extent of flow separation.

With extensive turbulence data available from the Driver experiments, the details of the turbulent flow development through the adverse pressure gradient region were investigated as shown in Figs. 7 - 9. The turbulent shear stress contours in Fig. 7 show that the SST solution delays the growth of $-\overline{u^{\prime} v^{\prime}}$ compared to the BSL solution and the solutions with varying $a_{1}$, particularly in the region $0 \mathrm{~mm}<x<100 \mathrm{~mm}$. This is the same region that, in Fig. 5, all of the pressure distributions from solutions other than the SST model begin to depart from the experimental data. One might conclude that $a_{1}=0.31$ utilized by the original SST model is capturing the flow physics most accurately. However, by examining contours of $-\overline{u^{\prime} v^{\prime}} / k$ (Fig. 8), which is equal to $a_{1}$, one can clearly see that none of the solutions, including the original SST model, accurately reproduce the experimental measurements. The experimental results show that $-\overline{u^{\prime} v^{\prime}} / k$ drops slightly near the beginning of the adverse pressure gradient region $(x=-300 \mathrm{~mm})$ and begins to increase near the end of the pressure gradient region $(x=200 \mathrm{~mm})$. This trend matches that found in other experiments. ${ }^{12,13}$ The Driver data, however, indicate that $-\overline{u^{\prime} v^{\prime}} / k$ remains substantially below 0.31 until well beyond the end of the domain.

The SST solution indeed limits $-\overline{u^{\prime} v^{\prime}} / k$ to 0.31 through most of the boundary layer, with a streak of $-\overline{u^{\prime} v^{\prime}} / k$ exceeding 0.31 where the model switches to the outer formulation and does not have a limit on $-\overline{u^{\prime} v^{\prime}} / k$. The SST solutions with $a_{1}>0.31$ and BSL solution allow for higher $-\overline{u^{\prime} v^{\prime}} / k$ lower in the boundary layer, as expected. The experimental measurements of turbulent kinetic energy in Fig. 9 show a much earlier increase over upstream levels (near $x=100 \mathrm{~mm}$ ) than any of the computational results. The turbulent shear stresses utilized in the original SST model that enable the best pressure distribution, result from applying a fortuitous limit (0.31) on a turbulent kinetic energy field that has responded too slowly to the adverse pressure gradient in comparison to the experimental data.

\section{Backward Facing Step}

We next examine the backward facing step case of Driver and Seegmiller. ${ }^{27}$ This case had flow at Mach 0.128 approaching the backward facing step region. Once again a grid taken from the turbulence modeling resource website was utilized here. A comparison of experimental measurements and computational results for skin friction in the vicinity of the step is shown in Fig. 10. There is little difference between the solutions when $a_{1}$ is increased to 0.34 and larger values. The slight difference in the BSL solution from the SST solutions with increased values for $a_{1}$ is due to the different value used for $\sigma_{k 1}$ than any of the SST-based solutions. Eddy viscosity contours for the two extreme cases, SST and BSL, are provided in Fig. 11.

In the experiments, laser Doppler velocimetry was used to obtain extensive data including turbulent stresses. Using their data which included $\overline{u^{\prime}}, \overline{v^{\prime}}$, and $-\overline{u^{\prime} v^{\prime}}$, an estimate for the turbulent kinetic energy can be made by assuming that $\sqrt{\overline{w^{\prime 2}}}=\frac{1}{2}\left(\sqrt{\overline{u^{\prime 2}}}+\sqrt{\overline{v^{\prime 2}}}\right)$. Figure 12 shows the calculated effective structure parameter $\left(-\overline{u^{\prime} v^{\prime}} / k\right)$ from the calculations and the data of Driver and Seegmiller. The experimental data shows a streak of $-\overline{u^{\prime} v^{\prime}} / k$ of approximately 0.35 extends across the shear line originating from the step to $x / H=2.5$, and while the peak value drops going further downstream, a streak where $-\overline{u^{\prime} v^{\prime}} / k$ exceeds 0.31 extends to $x / H=8$. 
Focusing on the region in the separation beyond the step, one may observe that the SST solution with $a_{1}=0.355$ and BSL solution predict slightly higher levels of $-\overline{u^{\prime} v^{\prime}} / k$ near $2 \leq x / H \leq 4$ than the standard SST solution. However, none agree well with the experimental data which indicate higher levels of $-\overline{u^{\prime} v^{\prime}} / k$ near the wall. This likely leads to the differences between experiment and computation for skin friction coefficient in the separated region.

\section{Mach 2.25 SWTBLI}

As stated in the introduction, the primary problem for which we suspect that limiting $a_{1}$ has had a detrimental effect is flows involving SWTBLIs. One of two SWTBLI configurations considered in the previously mentioned AIAA workshop was a test case obtained at the Institut Universitaire des Systemes Thermiques Industriels (IUSTI) in Marseille, France. ${ }^{28}$ The experimental data was part of the European Union SWTBLI research project referred to as UFAST. ${ }^{29}$ The UFAST experiments utilized an 8 degree shock generator which spanned the entire width of the tunnel with an approaching Mach 2.25 flow. The supply stagnation pressure was $50.5 \mathrm{kPa}$ and the stagnation temperature was $293 \mathrm{~K}$. Particle Image Velocimetry (PIV) was utilized to measure mean velocities and also obtain turbulent statistics. A three-dimensional computational grid was constructed having approximately 7.4 million points, and the average $y+$ of the first point off of the wall set to 1. A grid sensitivity study indicated minimal differences between solutions obtained with this grid and solutions using a sequenced grid, that is using every other point in each of the three computational directions.

In addition to simulations with the Menter BSL and SST models (using $a_{1}=0.31$ ), several other values for $a_{1}$ were investigated. A comparison of axial velocity contours from these simulations and experimental measurements is shown in Fig. 13. It may be observed that in all cases, the SWTBLI is centered around $x=320 \mathrm{~mm}$. Clearly the unmodified SST model provides an interaction region that is much larger than the experimental data and the BSL model indicates an interaction region that is too small. Table 1 provides a measure of the separation extent for the experimental data and CFD solutions that is obtained by examining where the axial velocity is negative at two vertical positions from the wall: $y_{1}=0.187 \mathrm{~mm}=0.017 \delta_{u}$ and $y_{2}=0.813 \mathrm{~mm}=0.074 \delta_{u}$. Examining these results and the contours in Fig. 13, it appears the solution obtained for $a_{1}=0.355$ provides the closest agreement with experimental data. Further comparison of axial velocity profiles in Fig. 14 supports these findings but also shows that none of the solutions agree well with the experimental data toward the end of the SWTBLI, where the flow is recovering to an attached state.

Table 1. Length of negative axial velocity streak for UFAST SWTBLI case. The vertical positions where the separation lengths were measured correspond to $y_{1}=0.187 \mathrm{~mm}=0.017 \delta_{u}$ and $y_{2}=0.813 \mathrm{~mm}=0.074 \delta_{u}$.

\begin{tabular}{lcc}
\hline Case & Separation Length-1 $(\mathrm{mm})$ & Separation Length-2 $(\mathrm{mm})$ \\
\hline \hline Experimental Data & 22.3 & 15.1 \\
Menter SST,$a_{1}=0.31$ & 52.9 & 43.1 \\
Menter SST, $a_{1}=0.34$ & 30.6 & 19.6 \\
Menter SST,$a_{1}=0.355$ & 24.6 & 13.5 \\
Menter SST, $a_{1}=0.37$ & 21.2 & 9.7 \\
Menter BSL & 16.0 & 0 \\
\hline
\end{tabular}

The experimental data suggests that raising $a_{1}$ closer to 0.355 is warranted. Figure 15 shows the behavior of $-\overline{u^{\prime} v^{\prime}} / k$ in the SWTBLI using the UFAST experimental data. As was the case for the backward facing step, $\sqrt{\overline{{w^{\prime 2}}^{2}}}$ was approximated as the mean of $\sqrt{\overline{{u^{\prime 2}}^{2}}}$ and $\sqrt{\overline{v^{\prime 2}}}$. Upstream of the interaction region, the attached boundary layer reaches a peak value for $-\overline{u^{\prime} v^{\prime}} / k$ that is slightly less than 0.30 , which is in agreement with the boundary layer findings mentioned earlier. In both the initial portion of the SWTBLI and then towards the latter half of the separation region $x>320 \mathrm{~mm}$, it may be observed that $-\overline{u^{\prime} v^{\prime}} / k$ increases well beyond the values characteristic of equilibrium boundary layers. It is interesting to note that for the profile nearest the center of the interaction, the peak value of $-\overline{u^{\prime} v^{\prime}} / k$ temporarily drops very low. It is not surprising then that the unmodified SST model with $a_{1}=0.31$ limits the turbulent shear stresses too much and results in a separated flow region that is too large. Humble et al. ${ }^{30}$ took PIV measurements for a similar SWTBLI flow problem and also observed similar increases in the turbulent shear stresses in the latter half of the 
SWTBLI and further downstream. These finding also agree with those of Refs. 19-21 which concluded that the turbulent stresses are amplified in the outer portion of the recovering boundary layer in SWTBLIs.

\section{Mach 5 SWTBLI}

We next examine the Mach 5 SWTBLI investigated experimentally by Schulein. ${ }^{31}$ Due to the significantly higher Mach number of this case, a detailed mapping of turbulent statistics was not available. Comparisons are limited to the skin friction through the SWTBLI.

The effect of variations in $a_{1}$ on the computed skin friction is provided in Fig. 16. None of the solutions match the experimental data very closely. All of the solutions predict a more rapid drop in skin friction coefficient than the experimental measurements in the region where the oblique shock intersects the boundary layer. Similar to the previously considered Mach 2.25 SWTBLI case, it is obvious again that the SST solution indicates the largest separation region and the BSL provides the smallest, with the same trends in separation extent resulting from variation in $a_{1}$.

\section{Scramjet Internal Flowpath}

The last case considered in this paper is the internal flowpath of a ground test scramjet configuration known as the Hypersonic International Flight Research Experimentation (HIFiRE) Direct-Connect Rig (HDCR). The configuration is a dual-mode scramjet test article with a long isolator, cavity flame holder, and multiple sets of fuel injectors. The case presented here simulates a flight Mach number of 5.8 and has an overall fuel equivalence ratio of 0.65 . Due to the harsh environment of this reacting flow configuration, only centerline pressure distributions are available from Ref. 32 for comparison.

A set of reacting flow test cases are compared. There are many factors in this case beyond SWTBLI that affect the resulting pressure distributions. These include thermal boundary layer effects, turbulent-chemistry interactions, and compressibility. However, as may be observed in Fig. 17(a), there is a significant SWTBLI region at the end of the isolator 8 in $\leq x \leq 15$ in which is where attention is focused here. The core flow Mach number approaching this region is 2.5. The comparison of pressure distributions in Fig. 17(b) shows a large discrepancy between the BSL and SST limits. For clarity, not all of the solutions are shown in the plot, but the trend is increasing pressure through the SWTBLI at the end of the isolator and beginning of the combustor as $a_{1}$ is increased, and the turbulent shear stress is permitted to be higher. The best agreement was provided by the case with $a_{1}=0.355$. While not shown here, a second case was examined for a freestream Mach number of 8.0, equivalence ratio $=1.0$, and core flow Mach number $=3.5$ approaching the end of the isolator. The behavior of the turbulence models was very similar with $a_{1}=0.355$ providing the best agreement.

\section{Conclusions}

The Menter Shear Stress Transport (SST) $k-\omega$ turbulence model has been one of the most successful and popular Reynolds-averaged Navier-Stokes turbulence models during the past two decades. A large reason for its success is in predicting wall bounded flows for a variety of flow conditions. Central to the model is the use of a limiter, which in the standard published version of the model prevents the turbulent shear stress from exceeding 0.31 times the turbulent kinetic energy in the inner part of a boundary layer. Menter's baseline (BSL) model does not limit the shear stress. Experience with the two otherwise nearly identical models has shown that for flows dominated by shock wave / turbulent boundary layer interactions (SWTBLIs), the SST model typically overestimates the size of flow separations while the BSL model underestimates separation magnitude. In this work, we examined the effect of the proportionality constant, $a_{1}$ which is used by the SST model to limit the turbulent shear stress.

A set of several nearly incompressible cases were investigated first, including a flat plate, axisymmetric diffuser, and backward facing step. In addition to examining the computational solutions, the details of the experimental results were also examined with focus placed on the turbulent shear stresses, turbulent kinetic energy, and their ratio, which is referred to as the structure parameter in the literature, and equivalent to $a_{1}$. For the low speed separating axisymmetric diffuser flow, the original SST model with $a_{1}=0.31$ yielded the best agreement in terms of pressure coefficient through the separation region. However, the experimental turbulence measurements for this case indicated that $a_{1}$ was substantially below this limiting value through 
the separation, and that the best agreement enabled by the SST model with $a_{1}=0.31$ may be considered fortuitous due to errors in all of the solutions in terms of accurately calculating the turbulent kinetic energy.

We then investigated the SWTBLI cases which were the motivation for this work. Experimental data for the UFAST test case, with Mach 2.25 flow approaching the oblique shock interaction, indicated that $-\overline{u^{\prime} v^{\prime}} / k$ exceeded 0.31 at the beginning of the SWTBLI and further downstream near reattachment. Also interesting was that the profile nearest the center of the interaction showed the peak value of $-\overline{u^{\prime} v^{\prime}} / k$ to temporarily drop. From the computations made with various values of $a_{1}$ in the SST limiter, the case with $a_{1}=0.355$ most closely matched the separation size from the experiments, and this choice for $a_{1}$ was consistent with the turbulent statistics from the experiment. A final case investigating a complex system problem of a direct connect scramjet experiment also showed that the SST model with $a_{1}=0.355$ provided the best agreement through the key shock-separated flow region.

As with many settings for key turbulence model coefficients, it is very difficult to find universal settings for all of the coefficients. The same is likely the case for the $a_{1}$ coefficient examined in this study. For the incompressible test cases considered, it is difficult to recommend a setting different than $a_{1}=0.31$ that is in the original formulation. However, it remains somewhat troubling that for the axisymmetric diffuser case, which was one of the showcase problems to recommend usage of the SST model, that the default value for $a_{1}$ is not consistent with experimental observation. For the range of SWTBLI cases investigated in this study, utilizing a value for $a_{1}$ closer to 0.355 yields improved predictions and is consistent with experimental observation for mean flow and turbulent statistics.

\section{References} 2010 .

${ }^{1}$ Benek, J., "Overview of the 2010 AIAA Shock Boundary Layer Interaction Workshop," AIAA Paper 2010-4821, January

${ }^{2}$ Benek, J. and Babinsky, H., "Lessons Learned from the 2010 AIAA Shock Boundary Layer Interaction Workshop," AIAA Paper 2010-4825, January 2010.

${ }^{3}$ DeBonis, J. R., Oberkampf, W. L., Wolf, R. T., Orkwis, P. D., Turner, M. G., Babinsky, H., and Benek, J. A., "Assessment of Computational Fluid Dynamics and Experimental Data for Shock Boundary-Layer Interactions," AIAA Journal, Vol. 50, No. 4, 2012, pp. 891-903.

${ }^{4}$ Menter, F. R., "Two Equation Eddy-ViscosityTurbulence Models for Engineering Applications," AIAA Journal, Vol. 32, No. 8, 1994, pp. 1598-1605.

${ }^{5}$ Wilcox, D. C., "Reassessment of the Scale-Determining Equation for Advanced Turbulence Models," AIAA Journal, Vol. 26, No. 11, 1988, pp. 1299-1310. 120.

${ }^{6}$ Townsend, A. A., "Equilibrium Layers and Wall Turbulence," Journal of Fluid Mechanics, Vol. 11, No. 1, 1961, pp. 97-

${ }^{7}$ Menter, F. R., "Improved Two Equation $k-\omega$ Turbulence Models for Aerodynamic Flows," NASA TM 103975, October 1992.

${ }^{8}$ Coakley, T. J., "Turbulence Modeling Methods for the Compressible Navier-Stokes Equations," AIAA Paper 83-1693, July 1983.

${ }^{9}$ Bradshaw, P., Ferriss, D. H., and Atwell, N. P., "Calculation of Boundary-Layer Development Using the Turbulent Energy Equation," Journal of Fluid Mechanics, Vol. 28, No. 3, 1967, pp. 593-616.

${ }^{10}$ Bradshaw, P., "The Turbulent Structure of Equilibrium Boundary Layers," Journal of Fluid Mechanics, Vol. 29, No. 4, 1967, pp. 625-645. 1955.

${ }^{11}$ Klebanoff, P., "Characteristics of Turbulence in a Boundary Layer with Zero Pressure Gradient," NACA Report 1247,

${ }^{12}$ Aubertine, C. D. and Eaton, J. K., "Turbulence Development in a Non-Equilibrium Turbulent Boundary Layer with Mild Adverse Pressure Gradient," Journal of Fluid Mechanics, Vol. 532, 2005, pp. 345-364.

${ }^{13}$ Alving, A. E. and Fernholz, H. H., "Turbulence Around a Mild Separation Bubble and Downstream of Reattachment," Journal of Fluid Mechanics, Vol. 322, 1996, pp. 297-328.

${ }^{14}$ Rose, W. G., "Results of an Attempt to Generate a Homogenous Shear Flow," Journal of Fluid Mechanics, Vol. 25, No. 1, 1966, pp. 97-120.

${ }^{15}$ Wilcox, D. C., "Formulation of the $k-\omega$ Turbulence Model Revisited," AIAA Journal, Vol. 46, No. 11, 2008, pp. 28232838.

${ }^{16}$ Wilcox, D. C., Turbulence Modeling for CFD, DCW Industries, 3rd ed., 2006.

${ }^{17}$ Tan, J. and Jin, J., "Stress Limiter Consideration for $k-\omega$ Turbulence Models in Shock Wave/Turbulent Boundary Layer Interactions in Supersonic and Hypersonic Flows ," AIAA Paper 2011-3980, June 2011. 
${ }^{18}$ Edwards, J. R., Choi, J. I., and Boles, J. A., "Large-Eddy / Reynolds-Averaged Navier-Stokes Simulation of a Mach 5 Compression-Corner Interaction," AIAA Journal, Vol. 46, No. 4, 2008, pp. 977-991.

${ }^{19}$ Smits, A. J. and Muck, K. C., "Experimental Study of Three Shock Wave / Turbulent Boundary Layer Interactions," Journal of Fluid Mechanics, Vol. 182, 1987, pp. 291-314.

${ }^{20}$ Jayaram, M., Taylor, M. W., and Smits, A. J., "The Response of a Compressible Turbulent Boundary Layer to Short Regions of Concave Surface Curvature," Journal of Fluid Mechanics, Vol. 175, 1987, pp. 343-362.

${ }^{21}$ Kuntz, D. W., Amatucci, V. A., and Addy, A. L., "Turbulent Boundary-Layer Properties Downstream of the Shock-Wave Boundary-Layer Interaction," AIAA Journal, Vol. 25, No. 5, 1987, pp. 668-675.

${ }^{22}$ Georgiadis, N. J., Yoder, D. A., Vyas, M. A., and Engblom, W. A., "Status of Turbulence Modeling for Hypersonic Propulsion Flowpaths," AIAA Paper 2011-5917, July 2011.

${ }^{23}$ Rumsey, C., Smith, B., and Huang, G., "Description of a Website Resource for Turbulence Modeling Verification and Validation," AIAA Paper 2010-4742, June 2010.

${ }^{24}$ Wieghardt, K. and Tillman, W., "On the Turbulent Friction Layer for Rising Pressure," NASA TM 1314, 1951.

${ }^{25}$ Driver, D. M., "Reynolds Shear Stress Measurements in a Separated Boundary Layer," AIAA Paper 91-1787, June 1991.

${ }^{26}$ Driver, D. M. and Johnston, J. P., "Experimental Study of a Three-Dimensional Shear-Driven Turbulent Boundary Layer with Streamwise Adverse Pressure Gradient," NASA TM 102211, May 1990.

${ }^{27}$ Driver, D. M. and Seegmiller, H. L., "Features of a Reattaching Turbulent Shear Layer in Divergent Channel Flow," AIAA Journal, Vol. 23, No. 2, 1985, pp. 163-171.

${ }^{28}$ Dupont, P., Piponniau, S., Sidorenko, A., and Debieve, J., "Investigation by Particle Image Velocimetry Measurements of Oblique Shock Reflection with Separation," AIAA Journal, Vol. 46, No. 6, 2008, pp. 1365-1370.

${ }^{29}$ Unsteady Effects in Shock Wave Induced Separation, edited by P. Doerffer, C. Hirsch, J.-P. Dussauge, H. Babinsky, and G. Barakos, Springer, 2010.

${ }^{30}$ Humble, R. A., Scarano, F., and van Oudheusden, B. W., "Experimental Study of an Incident Shock Wave / Turbulent Boundary Layer Interaction Using PIV," AIAA Paper 2006-3361, June 2006.

${ }^{31}$ Schulein, E., "Optical Skin Friction Measurements in Short-Duration Facilities," AIAA Paper 2004-2115, June 2004.

${ }^{32}$ Storch, A. M., Bynum, M., Liu, J., and Gruber, M., "Combustor Operability and Performance Verification for HIFiRE Flight 2," AIAA Paper 2011-2249, April 2011.

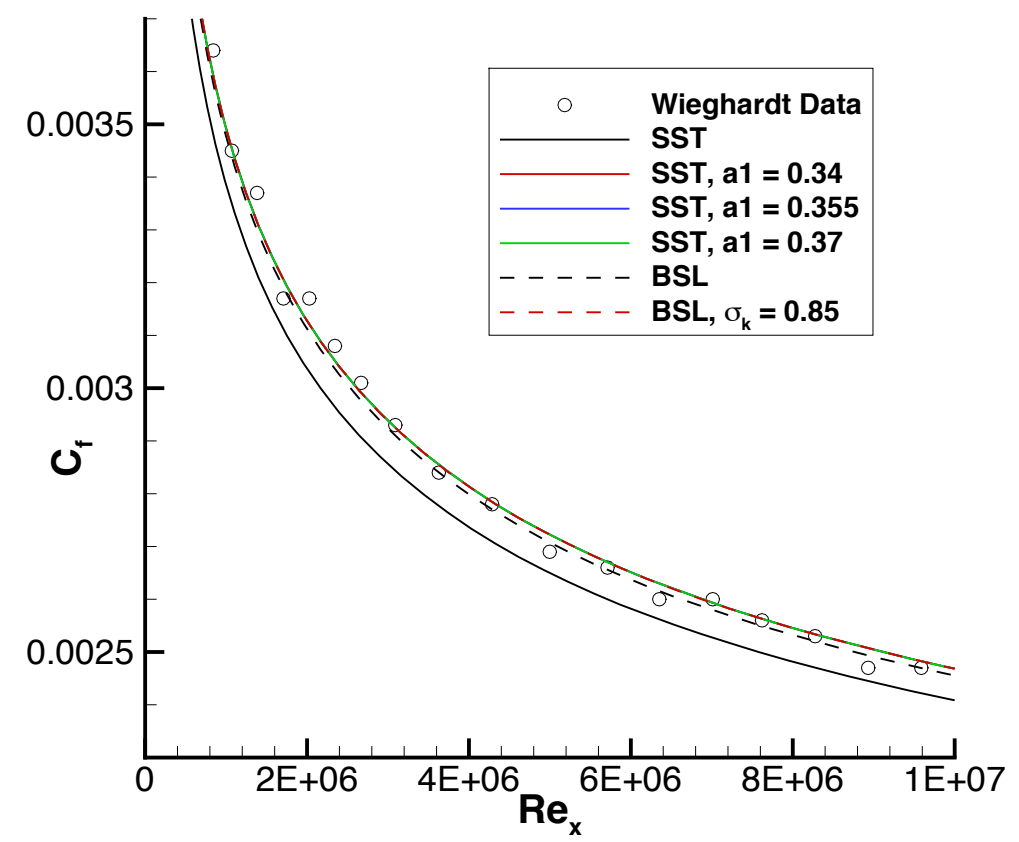

Figure 1. Skin friction for incompressible flat plate case. 


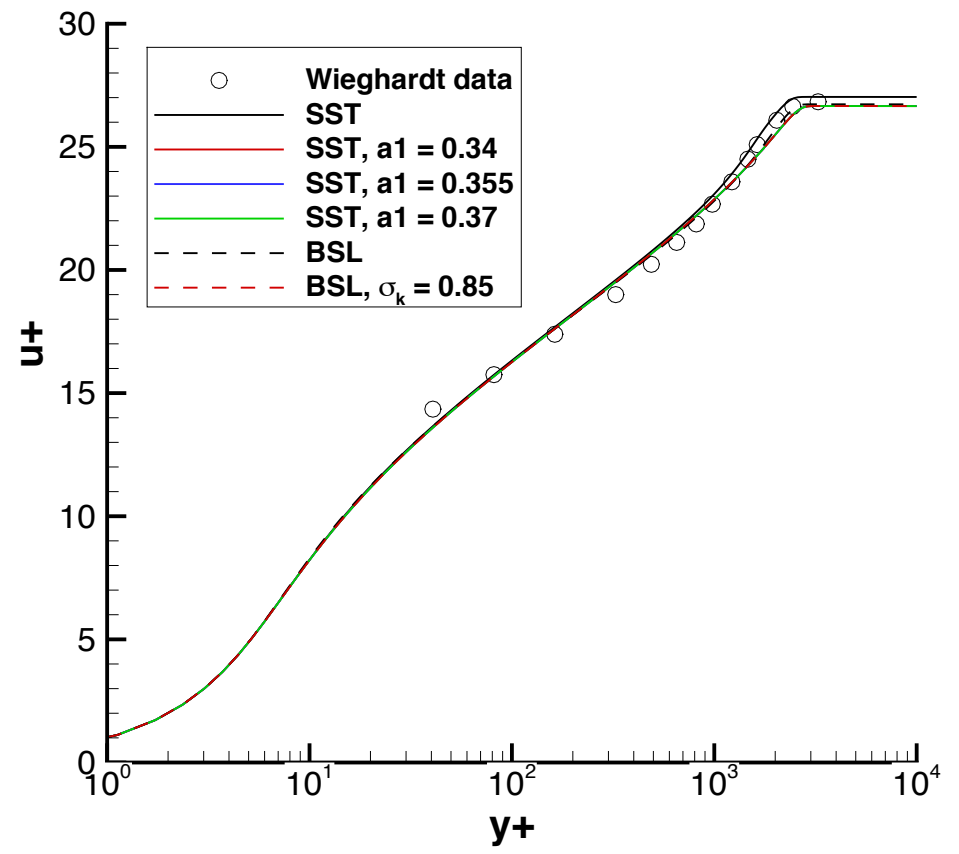

Figure 2. Velocity profile for incompressible flat plate case at $R e_{x}=4.3 \mathrm{e} 6$.

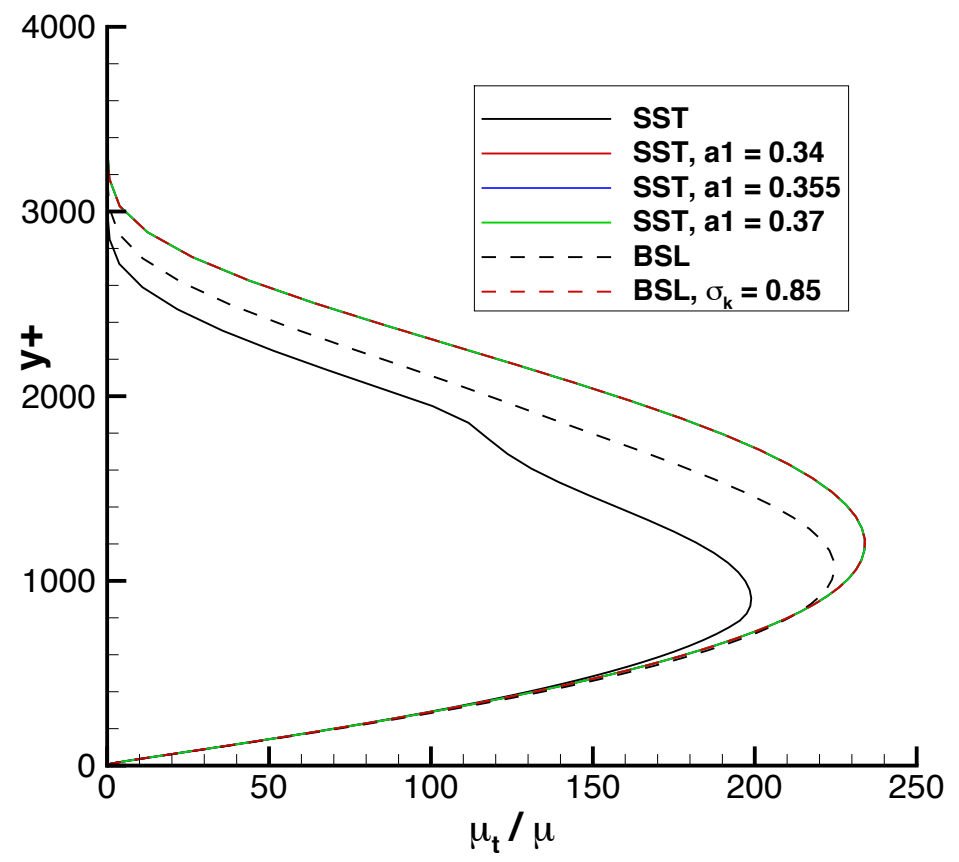

Figure 3. Eddy viscosity profiles at $R e_{x}=4.2 \mathrm{e}$. 


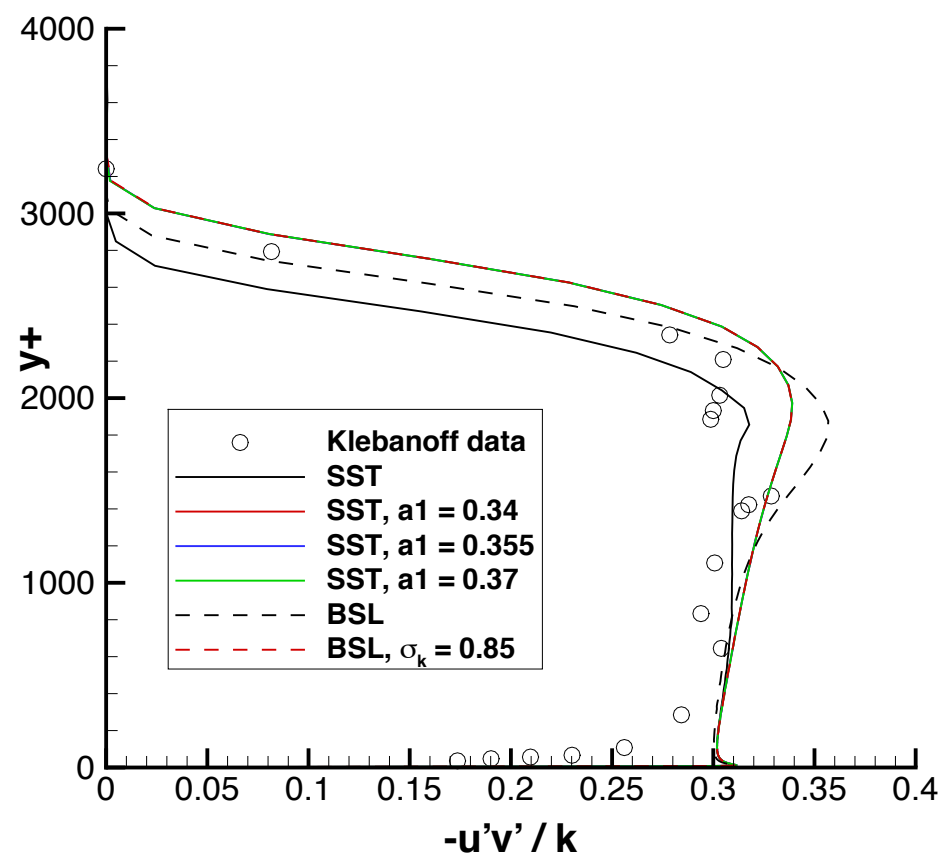

Figure 4. Turbulent shear stress profiles at $R e_{x}=4.2 \mathrm{e} 6$.

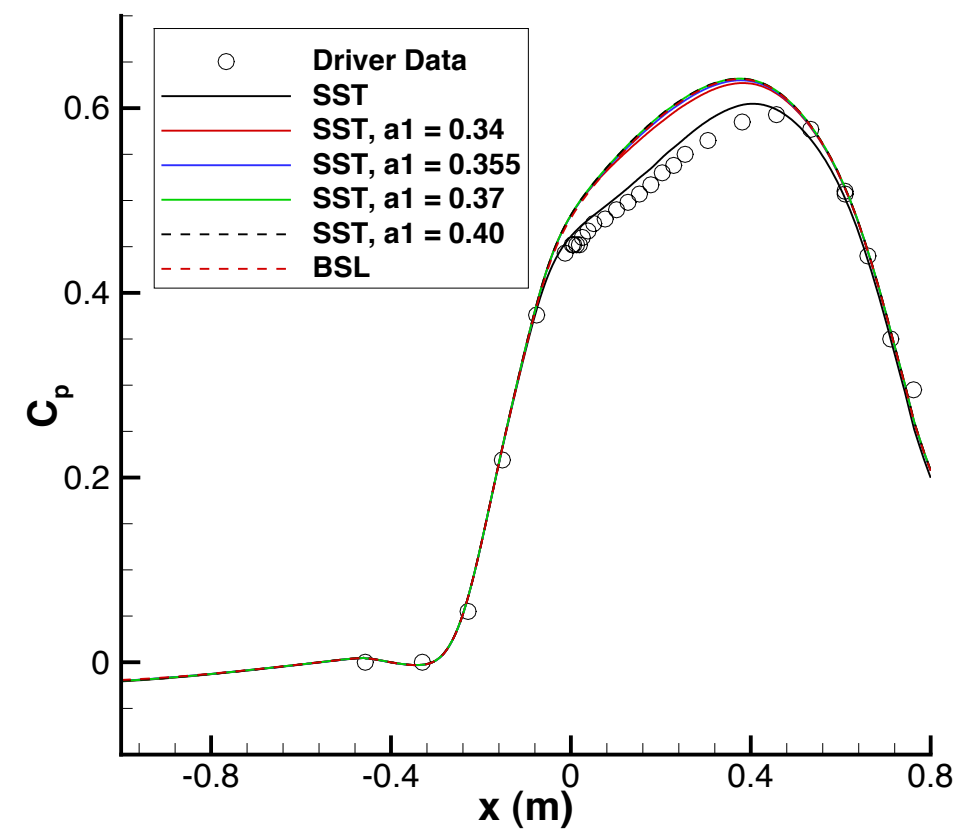

Figure 5. Wall pressure comparison for Driver axisymmetric diffuser. 


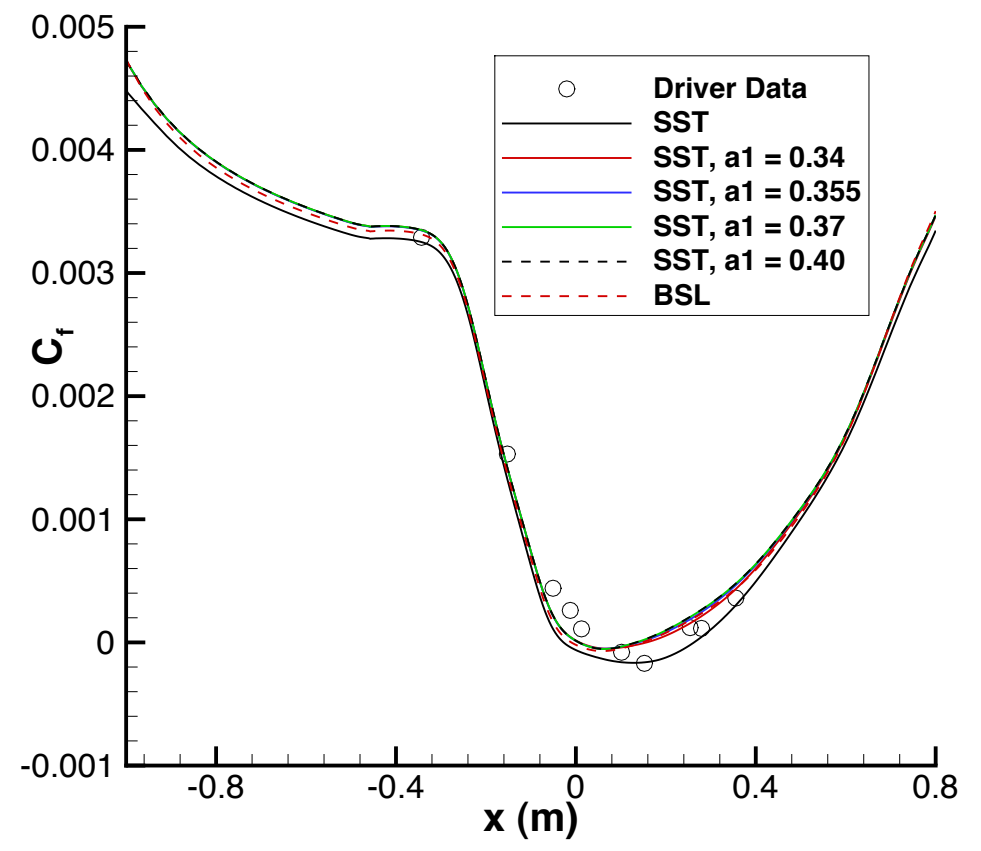

Figure 6. Skin friction comparison for Driver axisymmetric diffuser. 


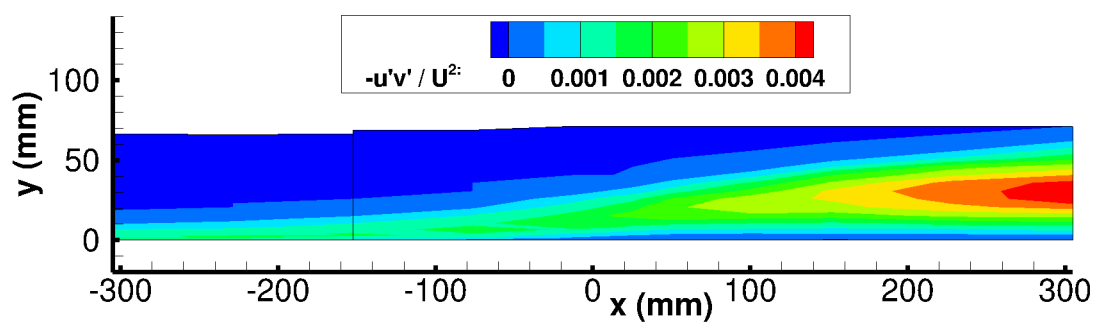

(a) Experiment

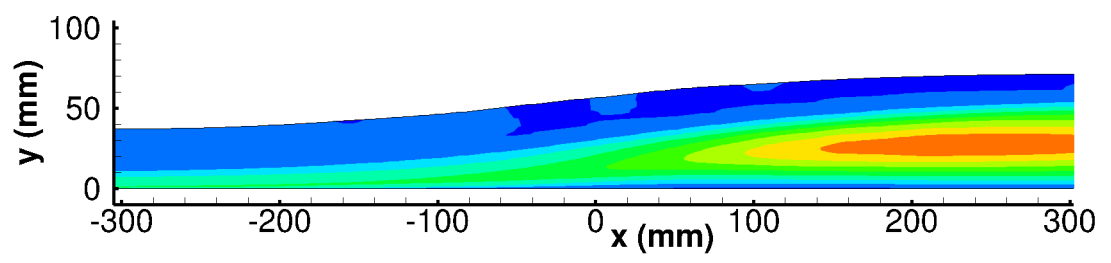

(b) SST

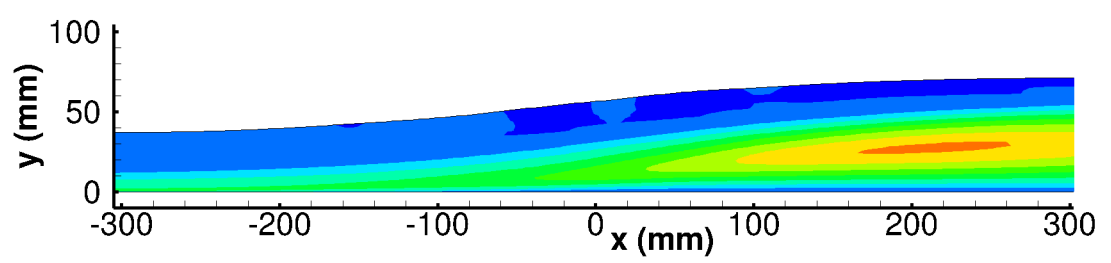

(c) SST, $a_{1}=0.34$

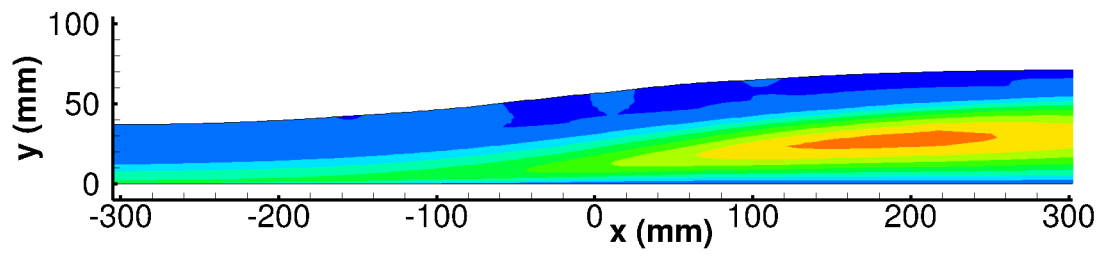

(d) SST, $a_{1}=0.355$

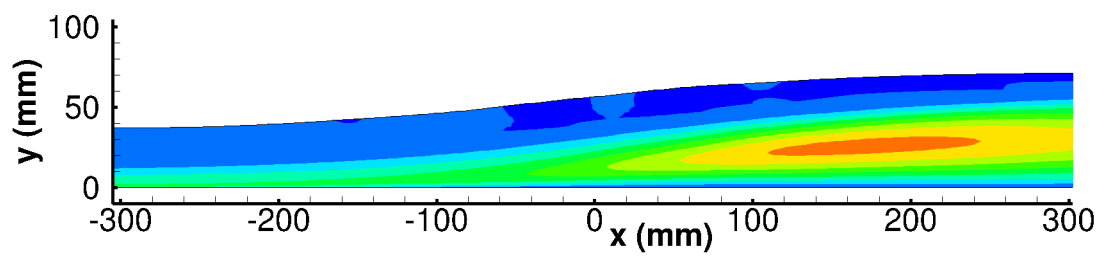

(e) SST, $a_{1}=0.37$

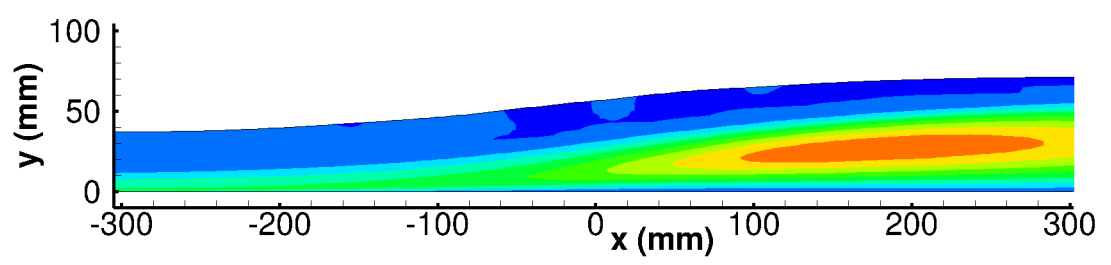

(f) BSL

Figure 7. Turbulent shear stress contours for Driver axisymmetric diffuser. 


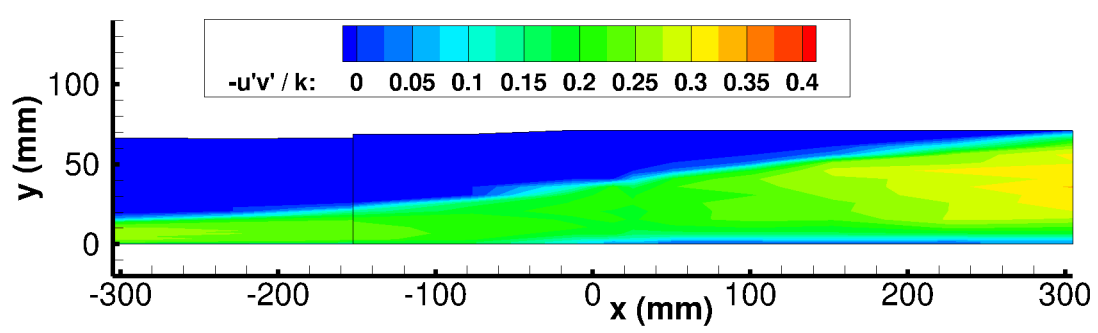

(a) Experiment

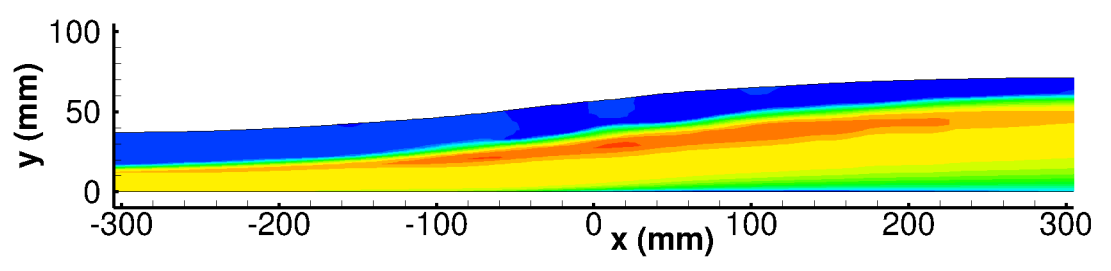

(b) SST

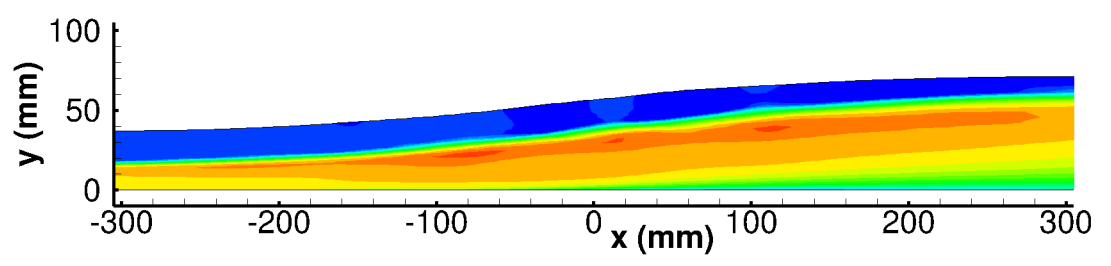

(c) SST, $a_{1}=0.34$

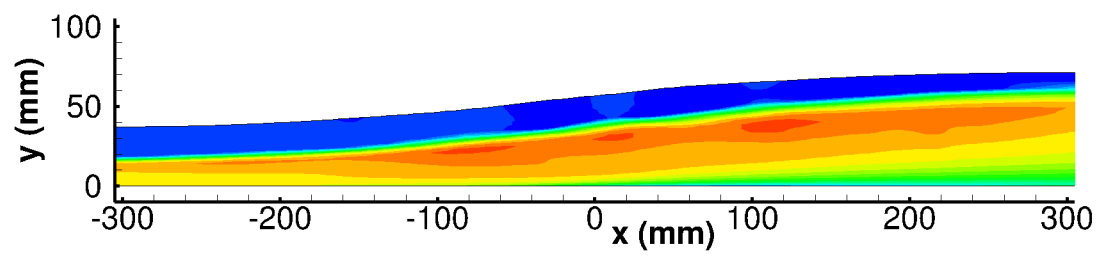

(d) SST, $a_{1}=0.355$

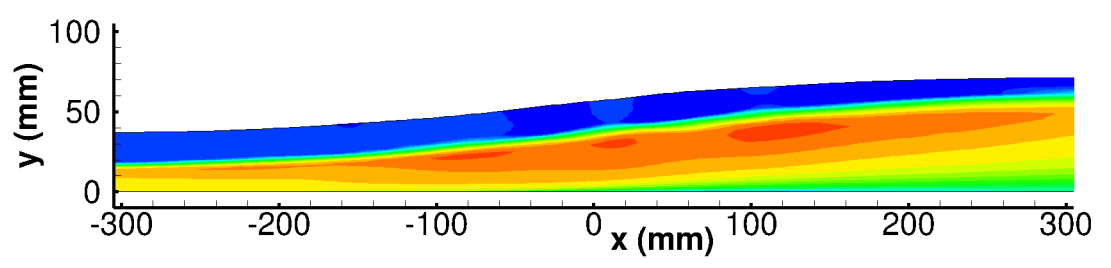

(e) SST, $a_{1}=0.37$

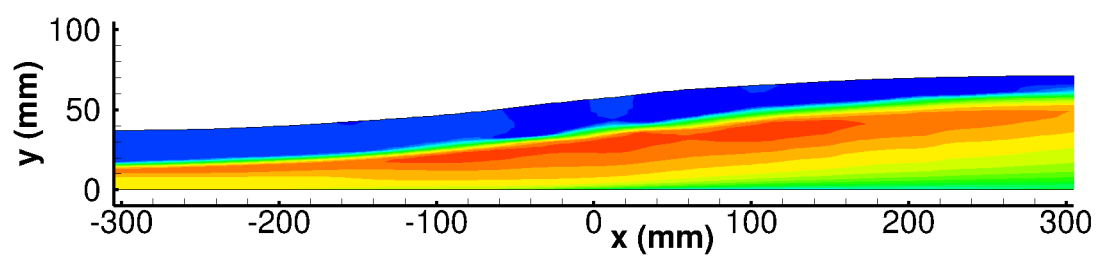

(f) BSL

Figure 8. Behavior of $-\overline{u^{\prime} v^{\prime}} / k$ for Driver axisymmetric diffuser. 


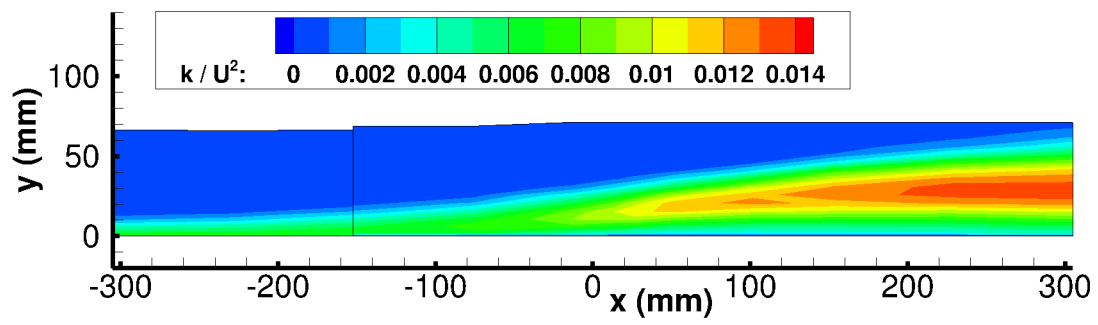

(a) Experiment

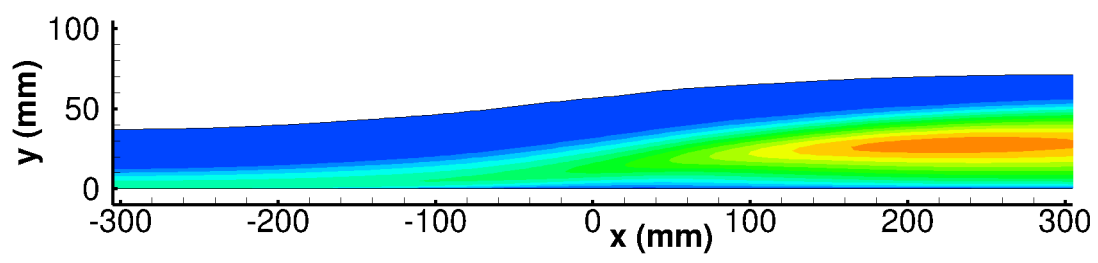

(b) SST

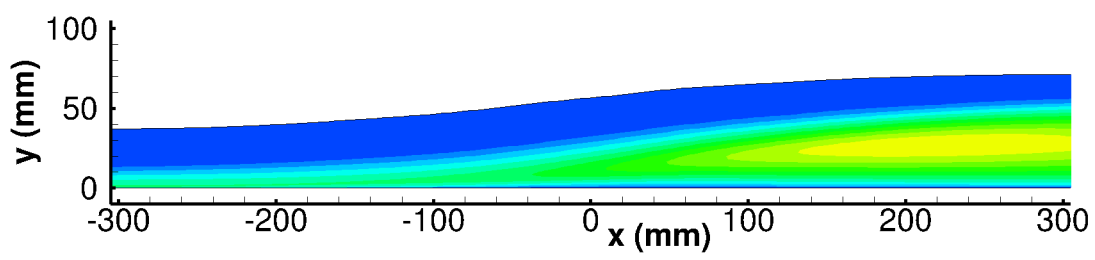

(c) $\mathrm{SST}, a_{1}=0.34$

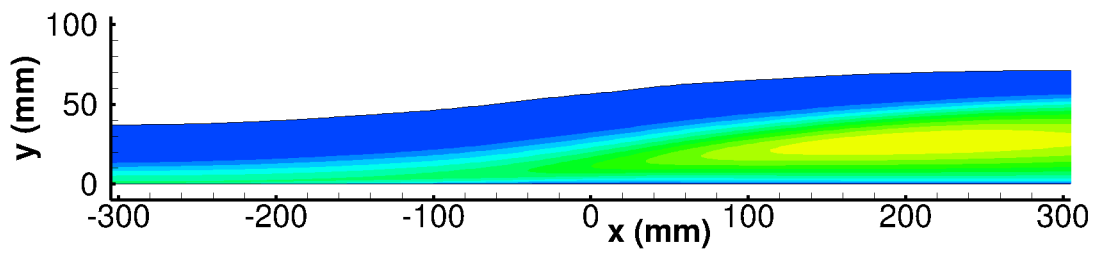

(d) SST, $a_{1}=0.355$

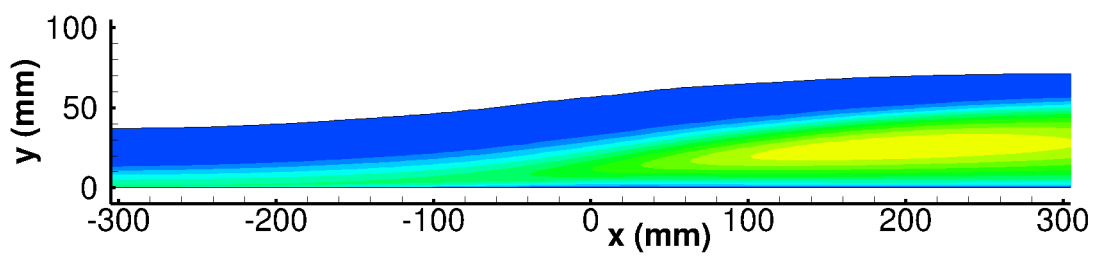

(e) SST, $a_{1}=0.37$

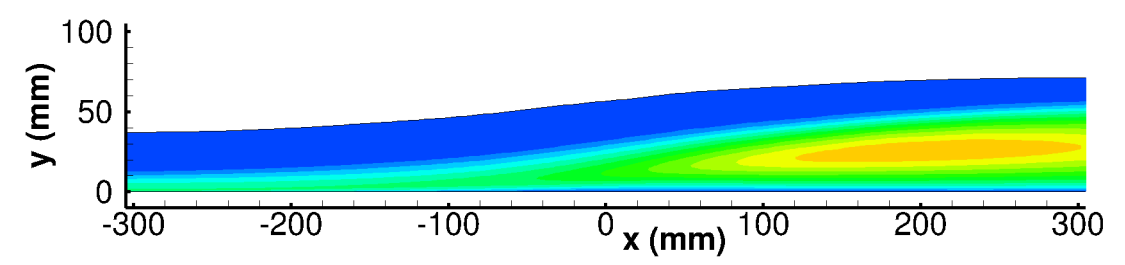

(f) BSL

Figure 9. Turbulent kinetic energy contours for Driver axisymmetric diffuser. 


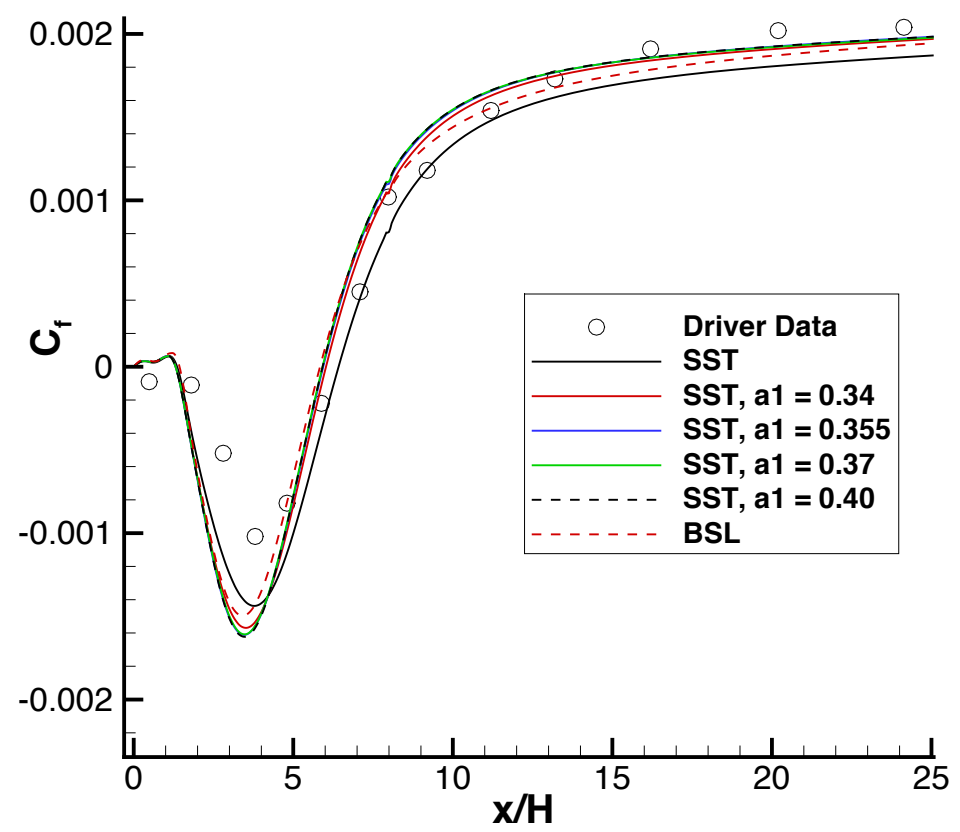

Figure 10. Skin friction coefficient for backward facing step.

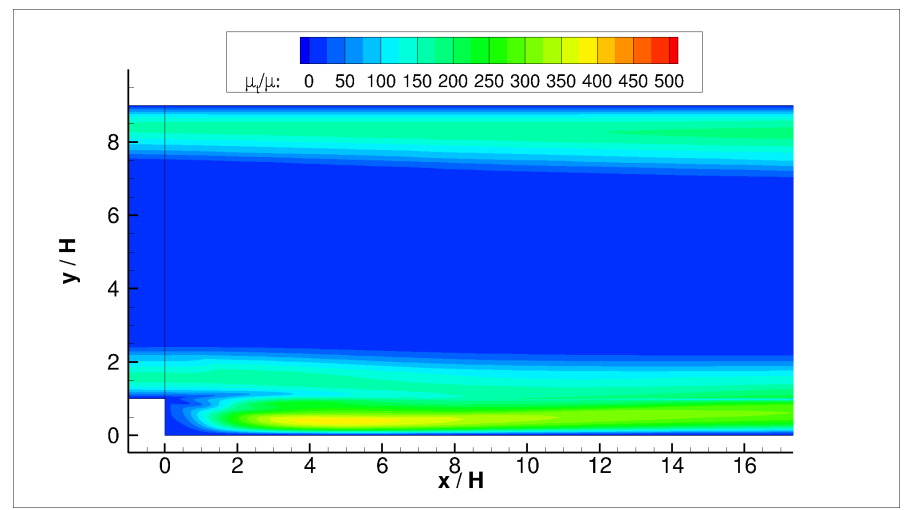

(a) SST

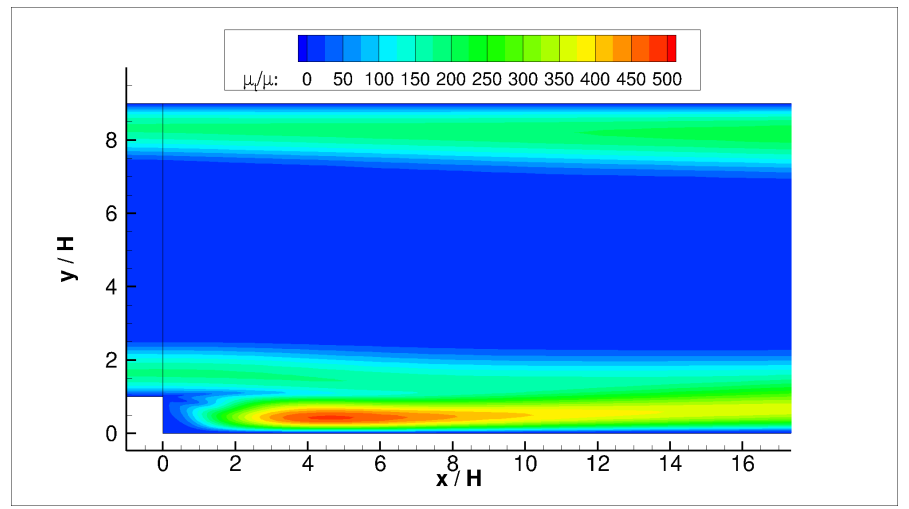

(b) BSL

Figure 11. Eddy viscosity contours for backward facing step. 


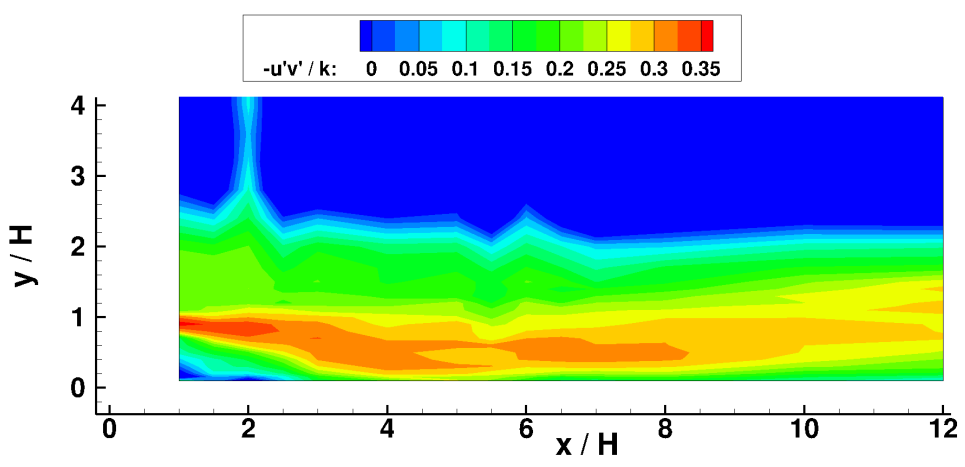

(a) Experiment of Driver and Seegmiller ${ }^{27}$

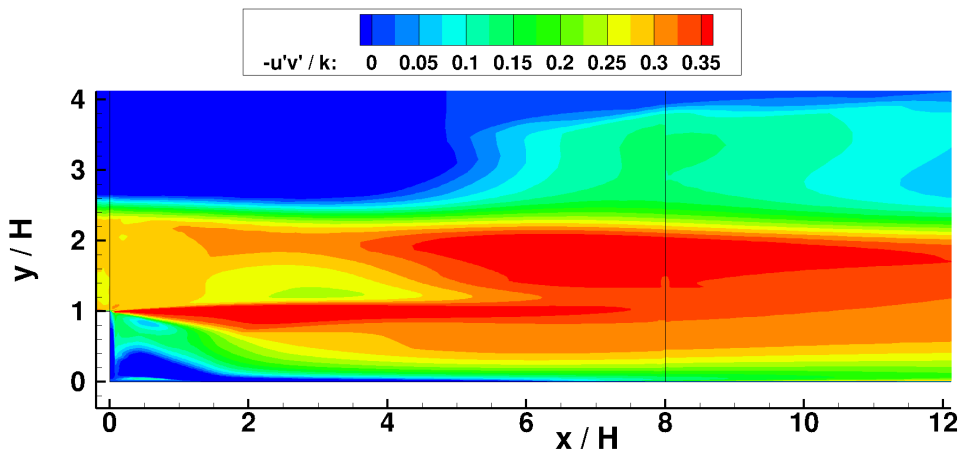

(b) SST

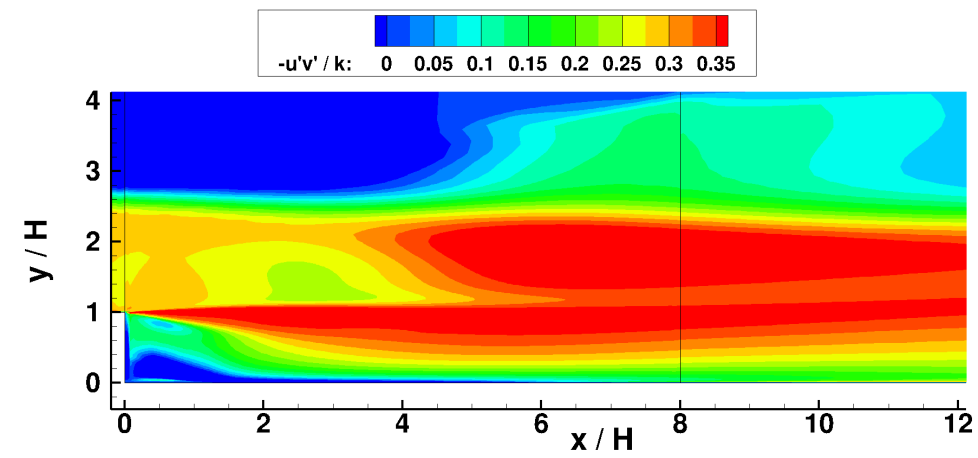

(c) SST, $a_{1}=0.355$

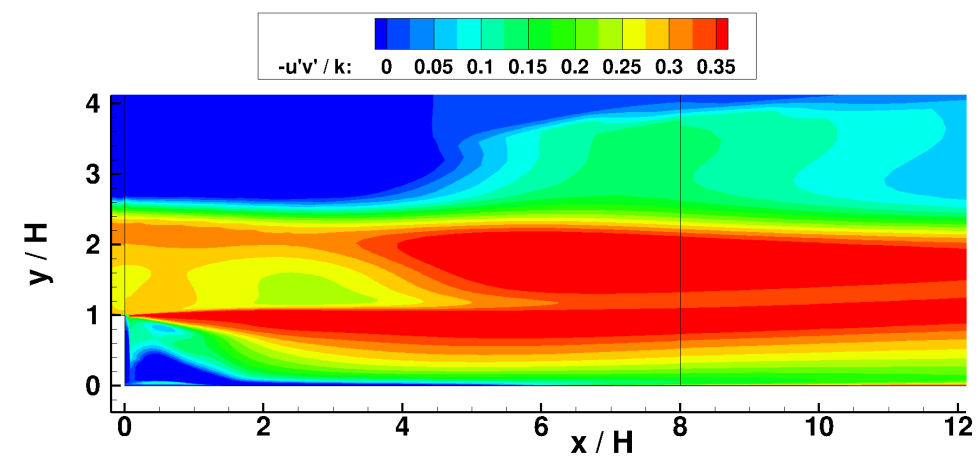

(d) BSL

Figure 12. Structure parameter for backward facing step. 


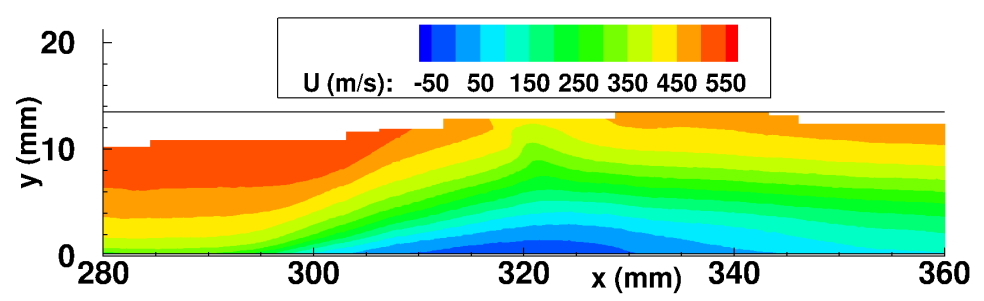

(a) Experiment

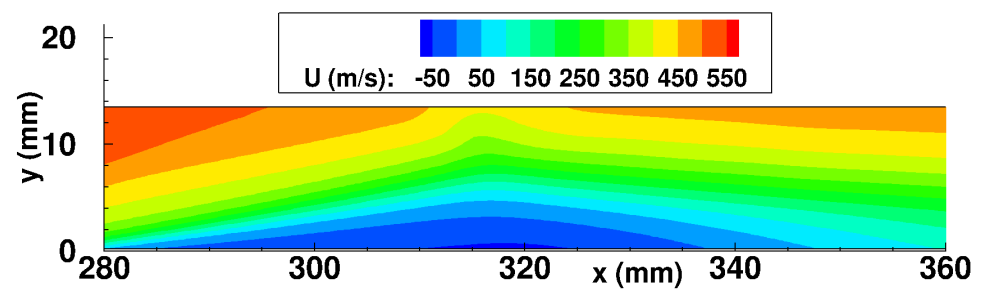

(b) SST

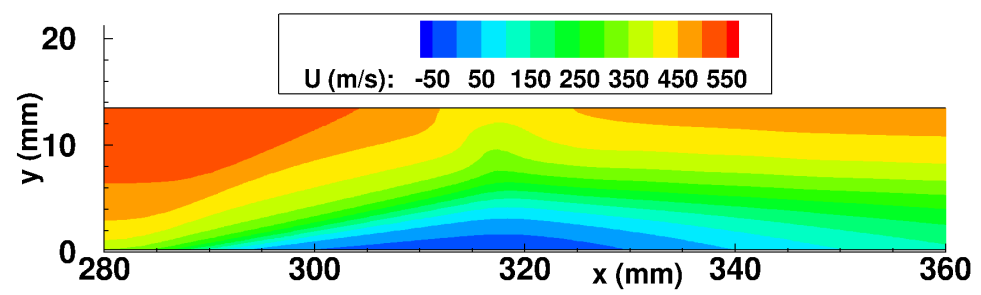

(c) SST, $a_{1}=0.34$

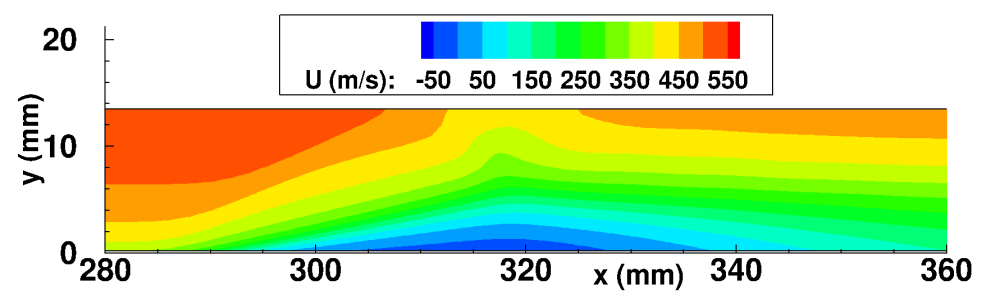

(d) SST, $a_{1}=0.355$

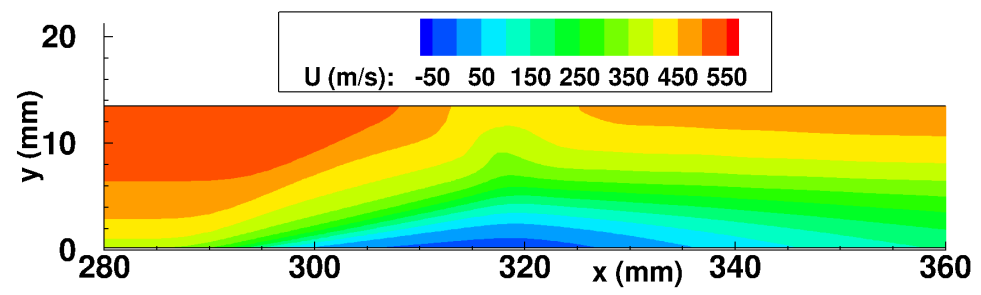

(e) SST, $a_{1}=0.37$

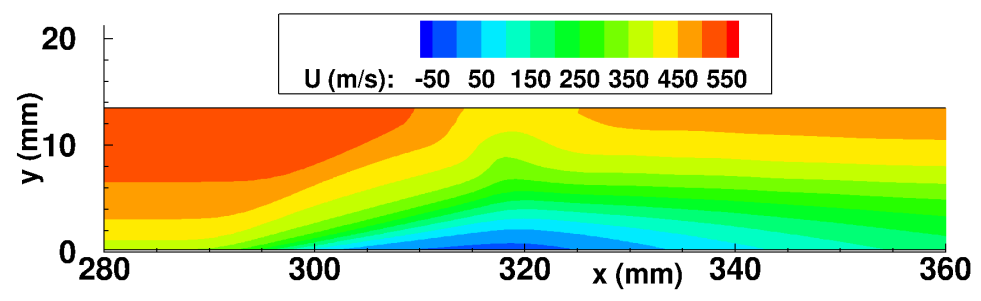

(f) BSL

Figure 13. Axial velocity contours for UFAST test case in vicinity of SWTBLI. 


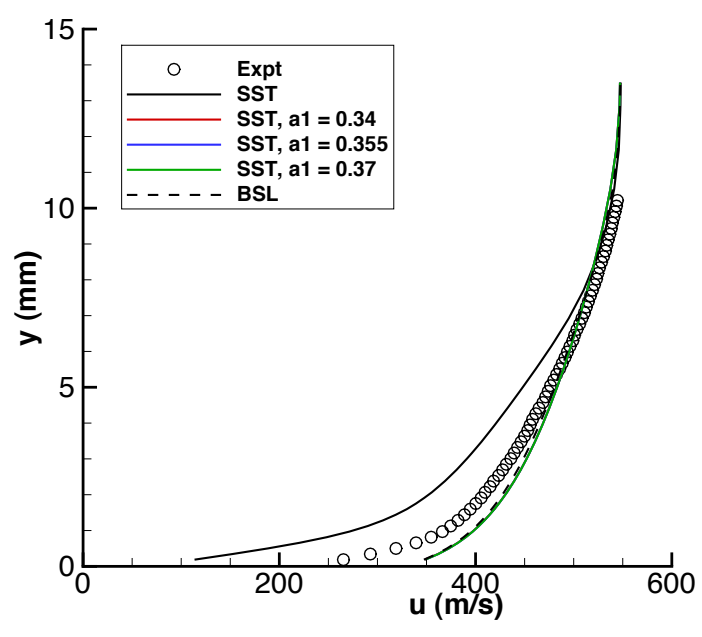

(a) $\mathrm{x}=280 \mathrm{~mm}$

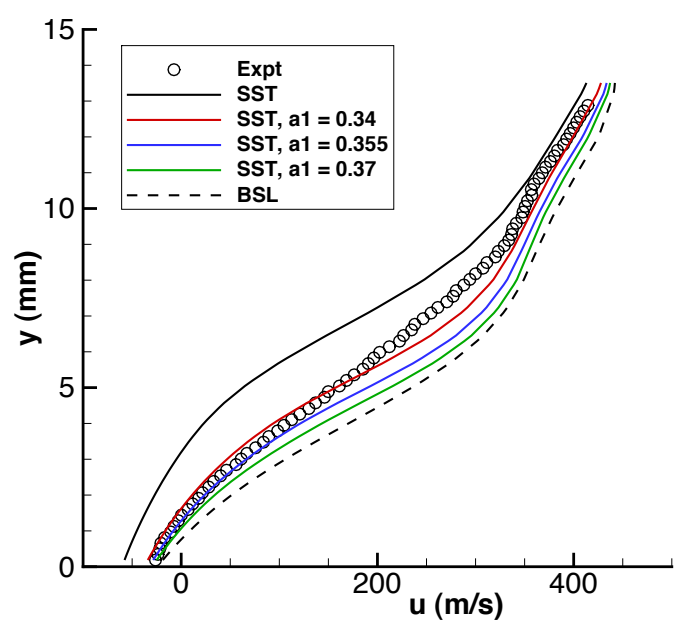

(c) $\mathrm{x}=320 \mathrm{~mm}$

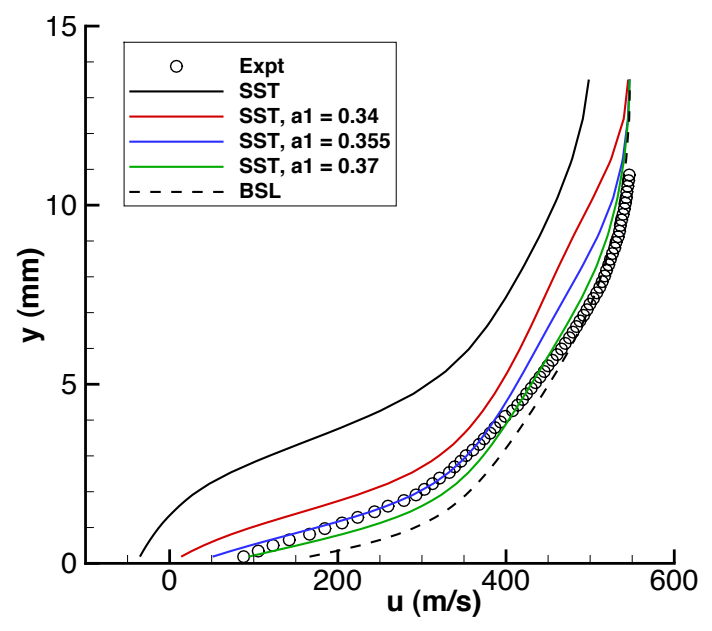

(b) $\mathrm{x}=300 \mathrm{~mm}$

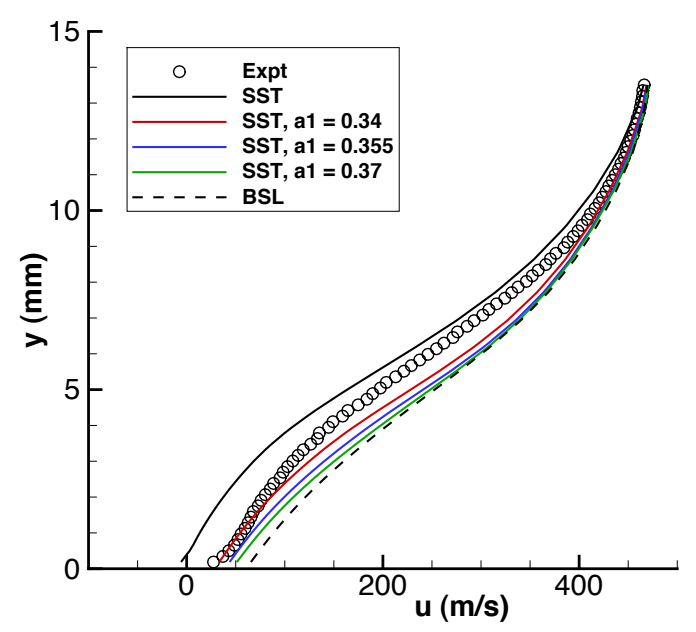

(d) $\mathrm{x}=340 \mathrm{~mm}$

Figure 14. Axial velocity profiles for UFAST test case in vicinity of SWTBLI. 


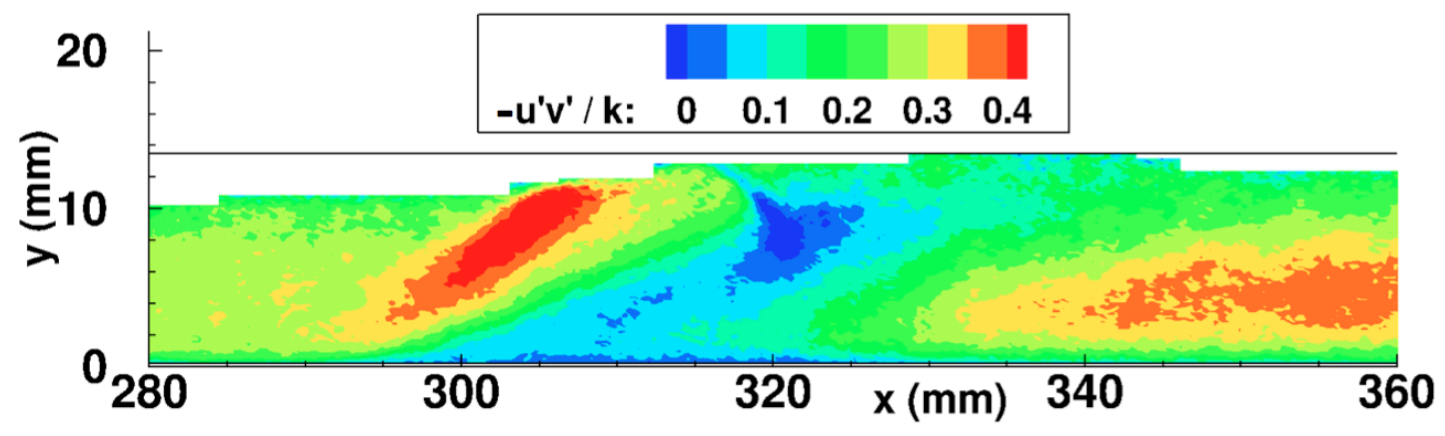

(a) Contours

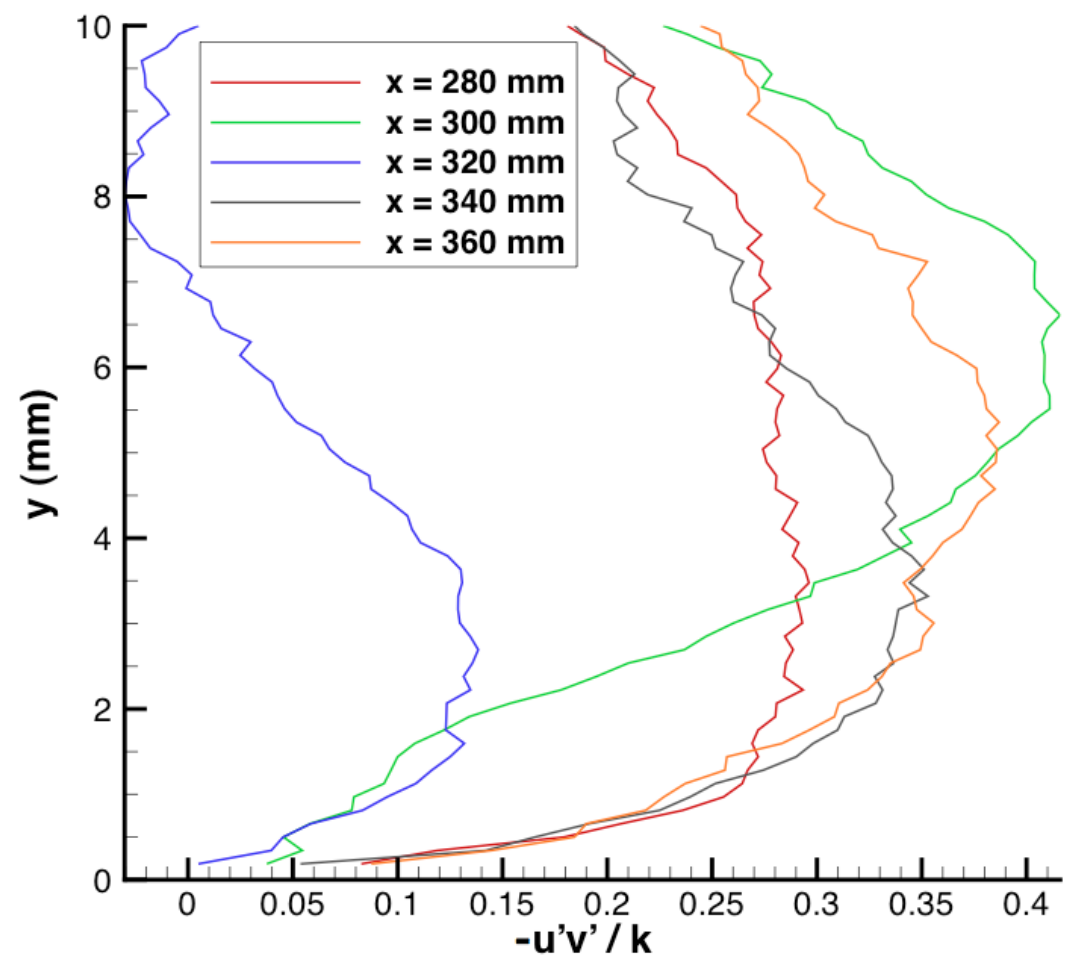

(b) Profiles at several axial stations

Figure 15. Behavior of $-\overline{u^{\prime} v^{\prime}} / k$ for UFAST case in vicinity of SWTBLI - taken from data of Ref. 29. 


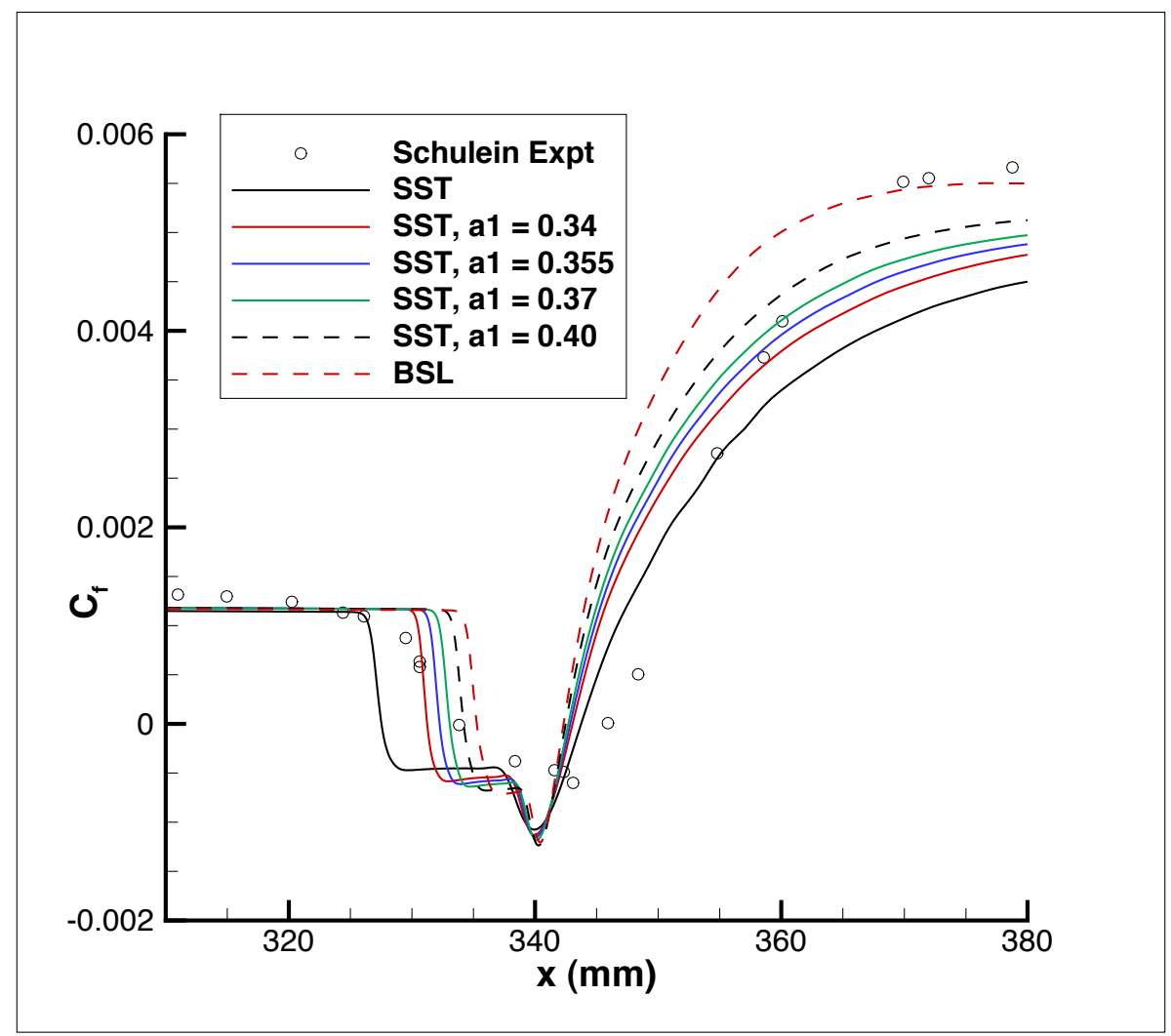

Figure 16. Skin friction for Mach 5 SWTBLI. 


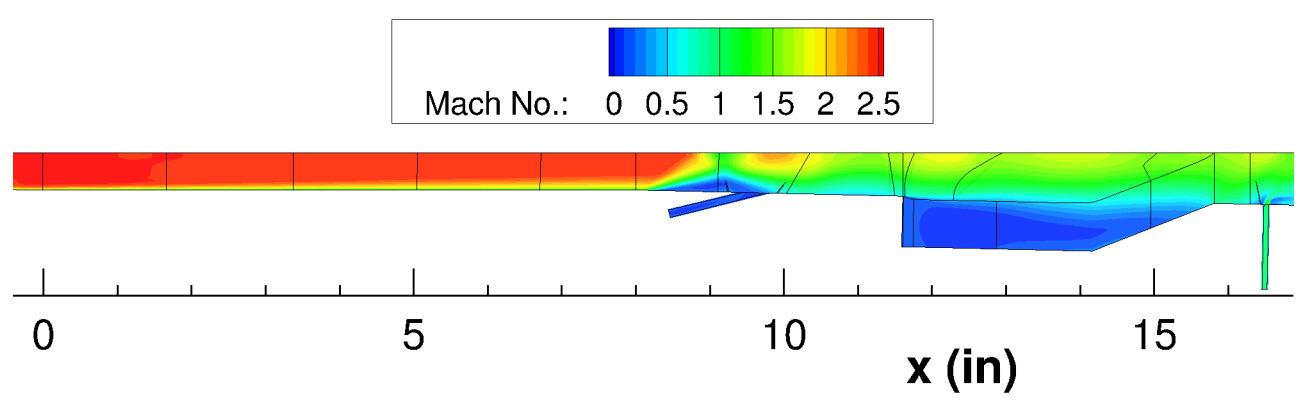

(a) Mach number contours along cut plane through fuel injectors

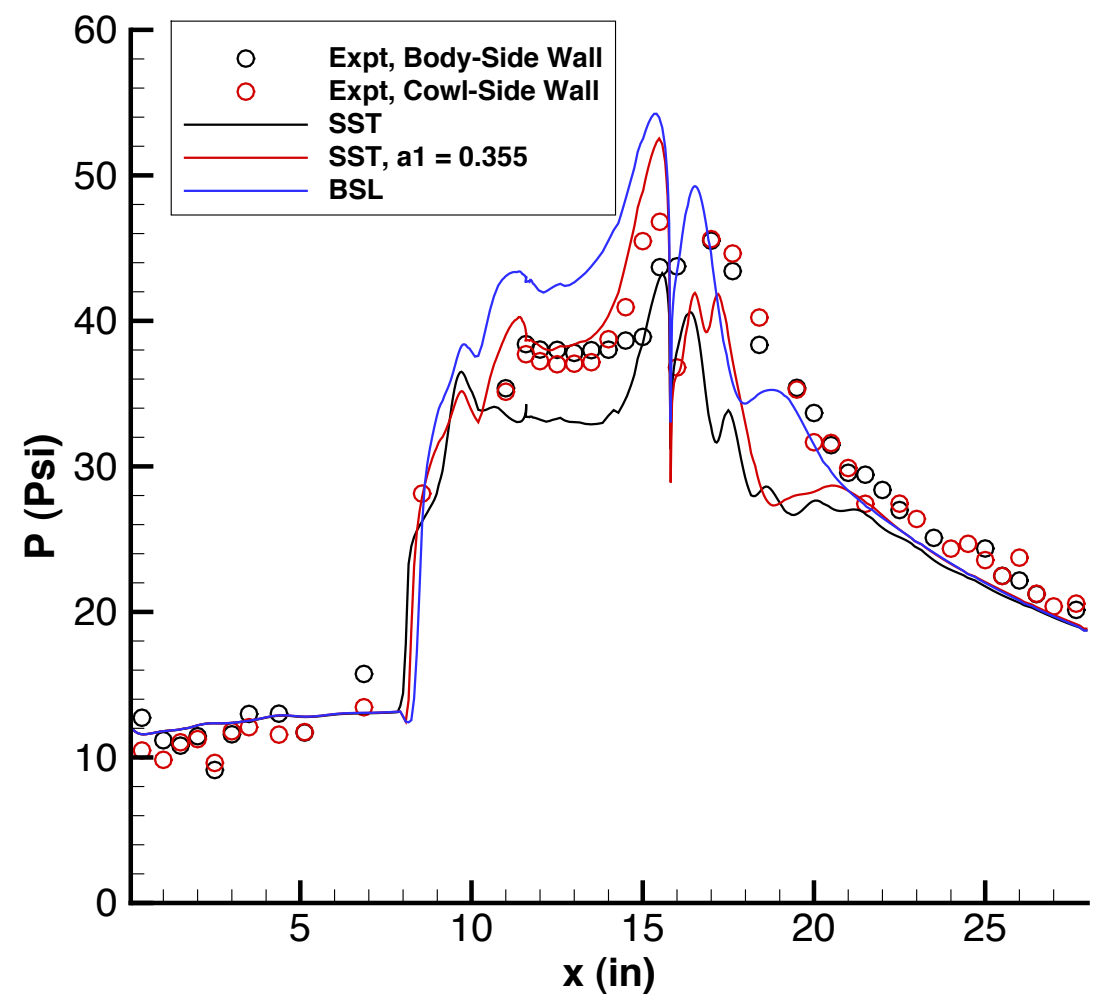

(b) Pressure comparisons along flowpath centerline

Figure 17. HIFiRE HDCR scramjet at Mach 5.8 freestream operating point. 


\begin{tabular}{|c|c|c|}
\hline \multicolumn{2}{|c|}{ REPORT DOCUMENTATION PAGE } & $\begin{array}{l}\text { Form Approved } \\
\text { OMB No. 0704-0188 }\end{array}$ \\
\hline \multicolumn{3}{|c|}{ 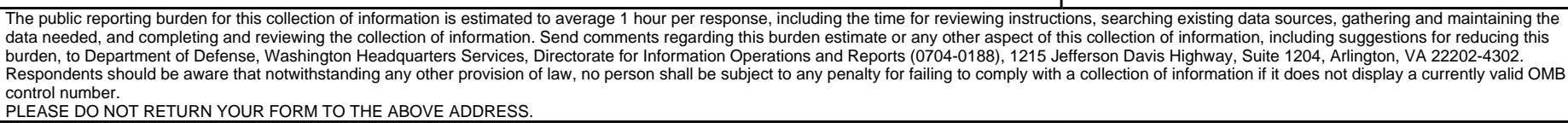 } \\
\hline $\begin{array}{l}\text { 1. REPORT DATE (DD-MM-YYYY) } \\
01-02-2013\end{array}$ & $\begin{array}{l}\text { 2. REPORT TYPE } \\
\text { Technical Memorandum }\end{array}$ & 3. DATES COVERED (From - To) \\
\hline \multirow{3}{*}{\multicolumn{2}{|c|}{$\begin{array}{l}\text { 4. TITLE AND SUBTITLE } \\
\text { Recalibration of the Shear Stress Transport Model to Improve Calculation of Shock Separated } \\
\text { Flows }\end{array}$}} & 5a. CONTRACT NUMBER \\
\hline & & 5b. GRANT NUMBER \\
\hline & & 5c. PROGRAM ELEMENT NUMBER \\
\hline \multirow{3}{*}{\multicolumn{2}{|c|}{$\begin{array}{l}\text { 6. AUTHOR(S) } \\
\text { Georgiadis, Nicholas, J.; Yoder, Dennis, A. }\end{array}$}} & 5d. PROJECT NUMBER \\
\hline & & 5e. TASK NUMBER \\
\hline & & $\begin{array}{l}\text { 5f. WORK UNIT NUMBER } \\
\text { WBS 794072.02.03.02.01 }\end{array}$ \\
\hline \multicolumn{2}{|c|}{$\begin{array}{l}\text { 7. PERFORMING ORGANIZATION NAME(S) AND ADDRESS(ES) } \\
\text { National Aeronautics and Space Administration } \\
\text { John H. Glenn Research Center at Lewis Field } \\
\text { Cleveland, Ohio 44135-3191 }\end{array}$} & $\begin{array}{l}\text { 8. PERFORMING ORGANIZATION } \\
\text { REPORT NUMBER } \\
\text { E-18639 }\end{array}$ \\
\hline \multirow{2}{*}{\multicolumn{2}{|c|}{$\begin{array}{l}\text { 9. SPONSORING/MONITORING AGENCY NAME(S) AND ADDRESS(ES) } \\
\text { National Aeronautics and Space Administration } \\
\text { Washington, DC 20546-0001 }\end{array}$}} & $\begin{array}{l}\text { 10. SPONSORING/MONITOR'S } \\
\text { ACRONYM(S) } \\
\text { NASA }\end{array}$ \\
\hline & & $\begin{array}{l}\text { 11. SPONSORING/MONITORING } \\
\text { REPORT NUMBER } \\
\text { NASA/TM-2013-217851 }\end{array}$ \\
\hline \multicolumn{3}{|c|}{$\begin{array}{l}\text { 12. DISTRIBUTION/AVAILABILITY STATEMENT } \\
\text { Unclassified-Unlimited } \\
\text { Subject Categories: } 02 \text { and } 34 \\
\text { Available electronically at http://www.sti.nasa.gov } \\
\text { This publication is available from the NASA Center for AeroSpace Information, 443-757-5802 }\end{array}$} \\
\hline
\end{tabular}

\section{SUPPLEMENTARY NOTES}

\section{ABSTRACT}

The Menter Shear Stress Transport (SST) $k-\omega$ turbulence model is one of the most widely used two-equation Reynolds-averaged NavierStokes turbulence models for aerodynamic analyses. The model extends Menter's baseline (BSL) model to include a limiter that prevents the calculated turbulent shear stress from exceeding a prescribed fraction of the turbulent kinetic energy via a proportionality constant, $a_{1}$, set to 0.31. Compared to other turbulence models, the SST model yields superior predictions of mild adverse pressure gradient flows including those with small separations. In shock - boundary layer interaction regions, the SST model produces separations that are too large while the BSL model is on the other extreme, predicting separations that are too small. In this paper, changing $a_{1}$ to a value near 0.355 is shown to significantly improve predictions of shock separated flows. Several cases are examined computationally and experimental data is also considered to justify raising the value of $a_{1}$ used for shock separated flows.

\section{SUBJECT TERMS}

Turbulence model; Shock-wave boundary layer interaction; Computational fluid dynamics

\begin{tabular}{|c|c|c|c|c|c|}
\hline \multicolumn{3}{|c|}{ 16. SECURITY CLASSIFICATION OF: } & \multirow{2}{*}{$\begin{array}{l}\text { 17. LIMITATION OF } \\
\text { ABSTRACT } \\
\text { UU }\end{array}$} & \multirow{2}{*}{$\begin{array}{l}\text { 18. NUMBER } \\
\text { OF } \\
\text { PAGES } \\
30\end{array}$} & \multirow{2}{*}{$\begin{array}{l}\text { 19a. NAME OF RESPONSIBLE PERSON } \\
\text { STI Help Desk (email:help@sti.nasa.gov) } \\
\text { 19b. TELEPHONE NUMBER (include area code) } \\
\text { 443-757-5802 }\end{array}$} \\
\hline $\begin{array}{l}\text { a. REPORT } \\
U\end{array}$ & $\begin{array}{l}\text { b. ABSTRACT } \\
U\end{array}$ & $\begin{array}{l}\text { c. THIS } \\
\text { PAGE } \\
\text { U }\end{array}$ & & & \\
\hline
\end{tabular}



